Portland State University

PDXScholar

1982

\title{
An investigation of the effects of self-disclosing communication on attraction-to-group in the small group setting
}

Pamela Walker Vredevelt

Portland State University

Follow this and additional works at: https://pdxscholar.library.pdx.edu/open_access_etds

Part of the Interpersonal and Small Group Communication Commons, Speech and Hearing Science Commons, and the Speech and Rhetorical Studies Commons Let us know how access to this document benefits you.

\section{Recommended Citation}

Vredevelt, Pamela Walker, "An investigation of the effects of self-disclosing communication on attractionto-group in the small group setting" (1982). Dissertations and Theses. Paper 3210.

https://doi.org/10.15760/etd.3201

This Thesis is brought to you for free and open access. It has been accepted for inclusion in Dissertations and Theses by an authorized administrator of PDXScholar. Please contact us if we can make this document more accessible: pdxscholar@pdx.edu. 
AN ABSTRACT OF THE THESIS OF Pamela Walker Vredevelt for the Master of Science in Speech Communications presented May 13, 1982.

Title: An Investigation of the Effects of Self-Disclosing Communication on Attraction-to-group in the Small Group Setting. APPROVED BY MEMBERS OF THE THESIS COMMITTEE:

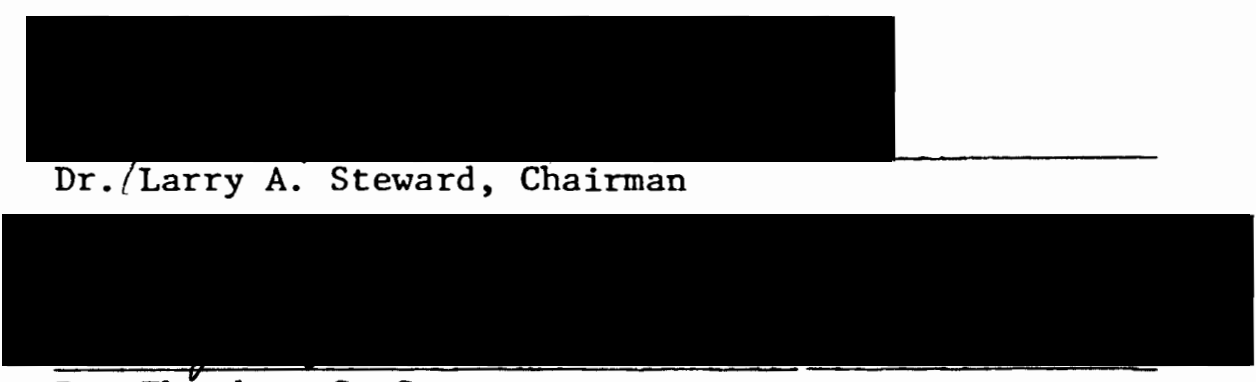

Dr. Theodore G. Grove

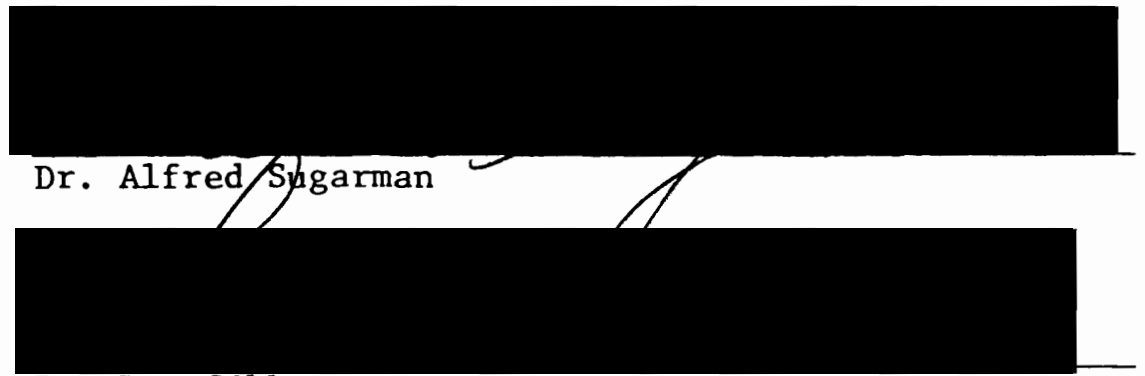

Dr. Don Gibbons

A review of the literature on self-disclosure and small group communication showed that few investigations dealt with the effects of disclosing communication on small group process. The present study was conducted in order to assess the effects of the frequency of self-disclosure within small groups on the members' overall attraction to the group. 120 subjects were selected from the East Hill Church senior high youth department in Gresham, Oregon. Subjects were placed at random into ten small groups with twelve members each which met for one-half hour per week for six consecu- 
tive weeks. All group communications were audio tape recorded. Weekly recordings were transcribed and rated for frequency of selfdisclosure. In addition, a self-report "attraction-to-group" measure was completed by all subjects at the end of each session in order to assess the attraction members felt for their groups each week.

The following three hypotheses were tested:

Hypothesis 1. Frequency of self-disclosure will increase over time in the small group setting.

Hypothesis 2. A strong positive association will be observed between initial frequency of self-disclosing communication and eventual degree of attraction-to-group. That is, higher frequencies of self-disclosure will be followed by greater attraction-to-group.

Hypothesis 3. Self-disclosure and attraction-to-group will co-vary over time, that is: 1. As self-disclosure increases, attraction-to-group will increase; 2. As self-disclosure decreases, attraction-to-group will decrease; and 3. As self-disclosure fluctuates, there will be a systematic fluctuation in attraction-to-group.

The three hypotheses were not confirmed by the data. Increased frequency of self-disclosure showed a low positive, but non-significant increase over time. Attraction-to-group scores fluctuated in a random pattern with no significant correlation with self-disclosure frequencies. The results indicated that while frequency of selfdisclosure in small groups may increase over time, lack of a controlled laboratory setting introduced uncontrolled sources of variation, 
which may have interfered with a fair test of the hypotheses. Results were not statistically significant. However, information from the present study provided methodological suggestions that may prove valuable for future research in this area. 
AN INVESTIGATION OF THE EFFECTS OF SELF-DISCLOSING COMMUNICATION ON ATTRACTION-TO-GROUP IN THE SMALL GROUP SETTING

$$
\text { by }
$$

PAMELA $W$. VREDEVELT

\footnotetext{
A thesis submitted in partial fulfillment of the requirements for the degree of
}

\author{
MASTER OF SCIENCE \\ in \\ SPEECH COMMUNICATION
}

Portland State Universtty 
TO THE OFFICE OF GRADUATE STUDIES AND RESEARCH:

The members of the Committee approve the thesis of Pamela Walker Vredeve1t presented May 13, 1982.

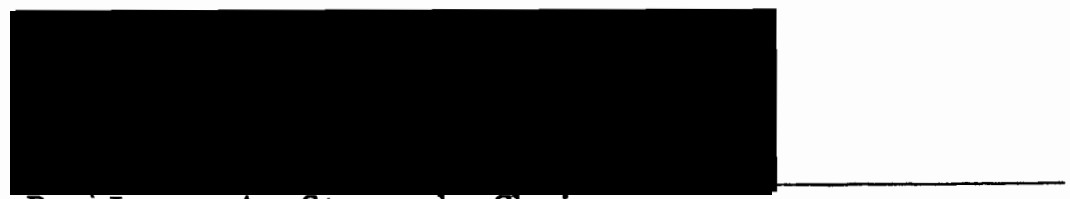

Dr. Larry A. Steward, Chairman

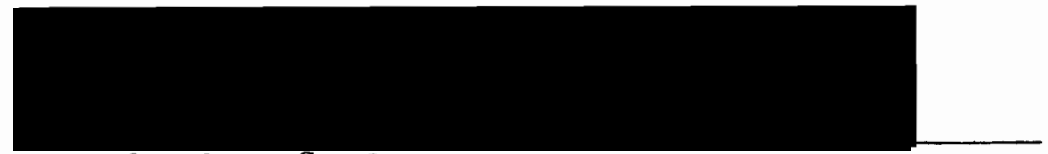

Dr. Theodore G.. Grove

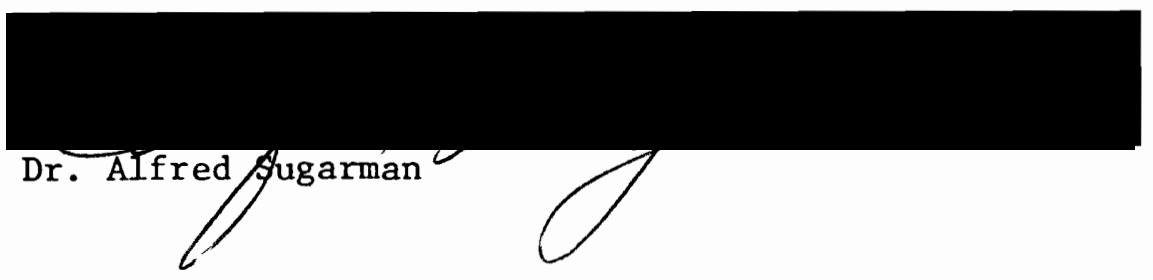

APPROVED :

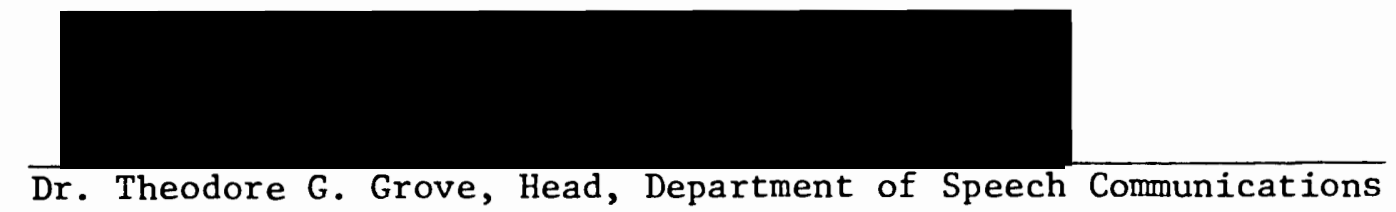

Dr. Stamley E. Rauch, Dean of Graduate Studies and Research 


\section{ACKNOWLEDGMENTS}

The writer would like to express her appreciation to the faculty of the Department of Speech Communication who gave their time, advice, and ideas to the study. Special credit is due to the following: to her thesis advisor, Dr. Larry Steward, for his sound advice and helpful assistance; to the members of her committee, Dr. Ted Grove and Dr. Alfred Sugarman, for their constructive counsel; to the representative for the Graduate Studies and Research Office, Dr. Don Gibbons, for his detailed stylistic suggestions; to her associate," Dr. Donald Howard, for his help in statistical procedures for data analysis; to her confederates, Ms. Deborah Greenidge, Ms. Tina Wilkerson, and the Senior High leaders at East Hill Church, for their dedicated help with the study; to her husband, Mr. John Vredevelt, who also serves as Youth Pastor at East Hill Church, for his enthusiastic participation in the investigation, and consistent encouragement, support, and devotion. 
TABLE OF CONTENTS

PAGE

ACKNOWLEDGMENTS. • . . . . . . . . . . . . . . . . . . iii

LIST OF TABLES . . . . . . . . . . . . . . . . . . . vi

LIST OF FIGURES. • . . . . . . . . . . . . . . . . . . . • . vii

INTRODUCTION . . . . . . . . . . . . . . . . . . . . . 1

Nature of the Study . . . . . . . . . . . . . . . . 1

Genesis of the Study. . . . . . . . . . . . . . . 2

\section{CHAPTER}

I THEORETICAL BACKGROUND . . . . . . . . . . . . . 6

Self-disclosure .................. 6

Definition and Usages. . . . . . . . . . . 6

Associated Variables . . . . . . . . . . . 8

Self-disclosure in Group Interaction. . . . . . . 8

Personality Characteristics and Self-disclosure . . .13

Social Situation and Self-disclosure. . . . . . . 15

Liking and Attraction and Self-disclosure . . . . .15

Psychotherapy and Self-disclosure . . . . . . . 18

Self-disclosure over time . . . . . . . . . .21

Measurement. . . . . . . . . . . . . . 24

Summary. . . . . . . . . . . . . . . . . 28

Application to the Present study . . . . . . . . . 29

Attraction-to-group . . . . . . . . . . . . . . 31

Definition and Usages. . . . . . . . . . . . 31

Theoretical Development. . . . . . . . . . . . 34

Measurement and Group Cohesion . . . . . . . . . 37

Sumary. . . . . . . . . . . . . . . . . .4 40

Application to the Present Study.......... . . . . . 1 
II.METHODS AND PROCEDURES . . . . . . . . . . . . . . . 42

Hypotheses . . . . . . . . . . . . . . . . 42

Design of the Study ................. . . . . . 2

Subjects . . . . . . . . . . . . . . . . 43

Group Discussion Topics. . . . . . . . . . . . 43

Training of Adult Facilitators . . . . . . . . . . 44

Training of Self-disclosure Co-rater . . . . . . . .45

Procedures:

Gathering the Small Group . . . . . . . . . .48

Measurement Procedures. . . . . . . . . . 49

III.RESULTS AND DISCUSSION . . . . . . . . . . . . . . . . . . . . . .

Hypothesis One .. . . . . . . . . . . . . . . 54

Hypothesis Two . . . . . . . . . . . . . . . 60

Hypothesis Three . . . . . . . . . . . . . 69

Summary . . . . . . . . . . . . . . . . . . 72

Participant Benefits of the Study . . . . . . . . . .74

Suggestions for Future Research . . . . . . . . . . 77

REFERENCES . . . . . . . . . . . . . . . . . . . . 79

APPENDIX . . . . . . . . . . . . . . . . . . . . . . . . . . . . . . 


\section{LIST OF TABLES}

TABLE

PAGE

I Frequency of Self-disclosure per Group, per Week . . . . . . .55

II Distribution of Group Means and Standard Deviation Index of Attraction-to-group . . . . . . . . . . . . . . .61

III Overall Correlations of Frequency of Self-disclosure with Attraction-to-group 


\section{LIST OF FIGURES}

FIGURE

PAGE

1 Examples of Rated Statements in the Three Disclosure Levels ... . 47

2 Stratified Random Field . . . . . . . . . . . . . . 50

3 Revised version of S.E. Seashore's Group Cohesiveness Index . . .52

4 Adult Small Group Member Questionaire . . . . . . . . . . . .53

5 Frequency of Self-disclosure per Group, per Week. . . . . . . . 55

6 Attraction-to-group and Self-disclosure Frequencies Graphed . . . 69 


\title{
INTRODUCTION
}

\author{
Nature of the Study
}

As humans we are social animals and it is not our nature to live alone. We were born into a group called the family and would not have survived the first few minutes, weeks, or years of our lives without membership in this group or in one similar to a family environment. Our personal survival as well as the survival of the species has always been linked to the inter-relationships formed among human beings. For many of us it is within the family and peer groups that we are socialized into ways of behaving and thinking, are educated, and acquire our outlook on the world and ourselves. Our personal development is partially derived from the way we are perceived and treated by other members of our groups. The quality of our lives depends in part upon the effectiveness of the groups to which we belong. This effectiveness in turn, is of ten determined by our personal group skills and understanding of group process (Johnson and Johnson, 1975).

Since a broadened awareness of group process and group skills may enhance the quality of one's daily interactions, studies concerning group process are necessary. As it is impossible to investigate all variables involved in group communication, the present investigation was limited to studying the relationship between two important variables involved in the group process: self-disclosure and attraction-to-group. The purpose of this study was to test the effects of one specific aspect of communication,. self-disclosure, upon one group process 
characteristic, attraction-to-group. Of particular importance was whether or not the frequency of self-disclosing communication among group members effects the members' overall attraction-to-the-group. Results from the present study should be beneficial to anyone attempting to maximize attraction-to-group in the small group setting.

\section{Genesis of the Study}

For the past five years the writer has been working with adolescents, functioning as an overseer in youth education at East Hill Church. The first year of leadership necessitated the establishment of positive relationships with approximately sixty Junior and Senior High young people who were regularly involved in weekly youth gatherings. These adolescents met one evening a week for activities and teachings. Over the years, attendance at these gatherings steadily increased to the present attendance of approximately 200 youth. With this development, it became apparent that it was impossible for the overseer to interact with each adolescent and that some of the young people were being lost in the crowd. Previous associations with other large youth groups gave the writer the awareness that bigness in terms of numbers in attendance doesn't always indicate either successful ministry or positive interaction among youth.

With these observations in mind the writer became involved in an evaluation process which took place over a period of several months. One result of the evaluation was the decision to restructure the Youth Department. It was decided that less emphasis would be placed on communication to the aggregate and more emphasis would be placed on small group communication. For this reason, each fall young people 
attending weekly gatherings were systematically divided into small groups. The groups remained intact for the course of the academic school year. The main function of these small groups was to allow youth a safe arena in which to interact and talk freely about the challenges and concerns of daily life. The mid-week youth meetings were structured in such a way as to allot two-thirds of the time for large group communication and one-third of the time for small group communication.

One of the main challenges involved in restructuring the youth group in this manner was to find adults willing and able to facilitate the small group discussions. It became obvious that some adult leadership training was necessary concerning small group communication process and skills. As a result of the writer's rather broad interest in communication and encouragement from Mr. Tom Erickson and Ms. Lynn Ludwig, professors at Multnomah School of the Bible in Portland, Oregon, a desire for further study began to take shape. Of particular interest was the development of personal skills in facilitating smáll groups, and acquiring an understanding of group process in order to train others for facilitating adolescent interaction in small group settings. One important question that needed answering was, "Why are some small group sessions effective and others not?" Stated another way, one can ask, "Why does one small group experience unity and closeness and another experience fragmentation?" These questions led the investigator to extensive reading in the small group research literature.

This survey of the literature revealed that two key variables thought to be extremely important to small group process are "self-disclosing communication" and "attraction-to-group." Not only were these 
variables prominent in the communication literature, but they were also of special interest to the investigator because of her background and experience in numerous group settings. An interesting phenomenon observed by the writer was the difference in the "chemistry" of the groups in which she was involved. Some groups seemed to be closely knit and were characterized by pleasant group participation. Others seemed to be rather dysfunctional, groping for survival, and less than stimulating. Another observation was that some group members frequently shared very personal information, while others remained impersonal in their communications. One might ask, "What relationship exists between the pleasant attraction felt in one group and the amount of "openingup' done by group members?" With these considerations in mind, the present study was designed to concentrate on self-disclosure in the small group setting and it's effects on the attractiveness of the group to its members.

For the purposes of this thesis self-disclosure was understood as any information about oneself which person $A$ verbally communicated to person B. Attraction-to-group was defined as the individual group member's desire to identify with and be an accepted member of the group. More specific definitions of the variables, self-disclosure and attraction-to-group, will be discussed in detail in the review of the literature.

As stated earlier, researchers have suggested that self-disclosure and attraction-to-group play important roles in the process of small group sessions. Accordingly, it seemed likely that a study focusing on these two variables in the small group setting would be beneficial in working with adolescents in the church. Specifically, the question 
considered was, "Does the frequency of self-disclosing communication effect the overall member's attraction-to-the-group?" A review of the literature concerning these two crucial variables will provide a broadened understanding of the foundation upon which the present study was based. 


\section{CHAPTER I}

\section{THEORETICAL BACKGROUND}

This chapter discusses a large sample of theory and quantitative research dealing with self-disclosure and attraction-to-group. The discussion that follows will focus on how the concepts are defined, their association with other relevant variables, their measurement, and their application to the present study.

\section{SELF-DISCLOSURE}

\section{Definition and Usages}

The concept of self-disclosure as an object of study has its roots in the existential and phenomenological philosophy of Husser1, Heidegger, Sartre, Buber, and Merleau-Ponty (Chelune, 1979). "To disclose" means to show, to make known, or to reveal. "Self-disclosure" is the act of making yourself manifest and showing yourself so others can perceive you (Jourard, 1971).

We are constantly encountering others face-to-face and disclosing many aspects of ourselves in the arena of daily experience. Without speaking, we reveal to others our height, weight, sex, approximate age, and possibly our mood (Rosenfeld, 1979). When engaging in conversation further disclosure takes place. This behavior of orally spoken disclosure has become synonymous with the term "self-disclosure" in the psychological and communication literature. Simply stated, according to Cosby (1973), self-disclosure may be defined as any 
information about himself or herself which Person A communicates verbally to person B. Other authors have modified Cosby's (1973) definition, further restricting the verbal disclosures that are considered "self-disclosing." Worthy, Gary, and Kahn (1969) define selfdisclosure as that which occurs when A knowingly communicates to B information about $\mathrm{A}$ which is not generally known and is not otherwise available to $B$. This definition further limits the parameter of disclosures to those that are intentional and private in nature. Pearce and Sharp (1973) distinguish self-disclosure from three other subsets of encoding behavior: non-disclosure, revealing and confession which limits disclosures to those that are voluntary. They exclude "confessions," communication behavior in which personal information is elicited from a person by force, threat, or drugs. "Revealing" behavior consisting of unintentional cues such as non-verbal mannerisms is also outside the limits of their definition. "Non-disclosures" are those communication strategies by which persons avoid being known by others (Pearce, et. al. 1973). A partial inventory of these forms include presenting false information about one's self, and a cluster of behaviors Gibb (1961) identified as "defensive." Gibb postulated that a small group has a defensive climate when high levels of evaluation, control, strategy, neutrality, superiority, and certainty are apparent.

It is clear from the above, that there are inconsistencies in the conceptual definitions used in self-disclosure research. To the extent that each operationally defines a somewhat different subset of selfdisclosing behaviors, different methods and assessment strategies become necessary. Since various studies used different definitions, it is not surprising that contradictory results are found in the literature. The 
significant findings of various studies will be discussed later.

Associated Variables

Group Interaction and Self-disclosure

Since the present investigation deals with self-disclosure in the small group setting, a brief review of literature in group studies involving disclosing communication should be undertaken. Aspects to be considered in this section are: 1. group interaction and the reciprocity of self-disclosure, 2. facilitator self-disclosure ín group interaction, and 3 . self-disclosure specifically tested in relation to small group intimacy and cohesion.

The survey of the literature revealed that self-disclosure is a major construct in the group process research. Findings contained in the encounter group and group therapy literature attest to the importance of the exchange of personal information, or self-disclosure among group members (Anchor, Vojtisek and Berger, 1972). Johnson (1963) and Egan (1970) identified self-disclosure as a vehicle for personal growth within a group. Anchor, Vojisek, and Berger (1972) assuming that self-disclosure is the basis for effective group psychotherapy, found that maximal productivity occurs when a certain ratio of disclosing and non-disclosing persons are preselected for the group.

One empirical finding that emerged with a marked degree of consistency was that, in certain contexts, verbalized self-disclosure does not occur capriciously. That is, self-disclosure apparently serves to stimulate further self-disclosure. Jourard (1960) used the term "dyadic effect" to describe reciprocal self-disclosure in two person interactions. 
Not only has the reciprocity of self-disclosure been found to occur in two person interactions, but the literature also documented a pattern of reciprocity occuring in experimental and therapy groups. Kangas (1971) found significant correlations between levels of selfdisclosure in selected statements made by therapy group members and the immediately preceeding comment of the therapist and other group members. Certner (1971) investigated the mutual exchange of selfdisclosure among the group members in the laboratory setting. He found significant correlations between the average intimacy level of disclosure that each subject received from and revealed to each of the other group members.

Strassberg, Gabel, and Anchor (1976) examined the sequence of interactions among group members in parent discussion groups. Results showed that the pattern of self-disclosing and non-self-disclosing statements was nonrandom. That is, a self-disclosing statement by group members tended to be preceded and/or followed by another selfdisclosing statement more frequently than would be expected by chance. Similarly, non-self-disclosing statements tended to cluster together more frequently than by chance. The analysis thus revealed a significant tendency for self-disclosing statements by group members to occur contiguously. When considered together with the previous research mentioned, it seems that reciprocity of self-disclosure among group members is a general phenomenon operating in a variety of group settings. For this reason, in the present investigation the writer focused on self-disclosure in relation to attraction-to-group. Chelune (1979) says, "Perhaps the most reliable and robust situational determinant of self-disclosure in any setting is the disclosure of another 
person or persons." This "reciprocity" or "dyadic" effect has been frequently demonstrated and seems to override the influence of any individual difference variables.

Reciprocity has been shown to effect the self-disclosure shared in group settings and to be a variable worthy of consideration. Another variable influencing the disclosure in small groups is disclosure made by the group facilitator. This is a controversial issue in the literature of group psychotherapy, personal growth and encounter groups. One of the main issues addressed in the literature concerns the relative advantages or drawbacks of "leader" self-disclosure. Theoretical positions range from complete therapeutic anonymity to total self-disclosure. Advocates of the "non-disclosure" style of facilitation include such practitioners inclined toward psychoanalytical approaches (e. g. Locke, Slavson, Wolff, and Schwartz, 1974), theorists oriented toward group dynamics (e. g. Lieberman, Yalom, and Miles, 1973), and practitioners of behavior therapies, Gestalt therapy, and psychodrama (Shaffer and Galinsky, 1974): These approaches emphasize leadership techniques and the role of the group conductor as overseer and manager of the group process. Personal relationships of the leader with group members is not a major focus.

On the opposite extreme of this continuum are group facilitators who endorse self-disclosure among group leaders. Psychotherapists in this area include existential theorists such as Hora, Mullan, and Gerger (Shaffer and Galinsky, 1974), humanists such as Jourard (1971), and encounter group leaders such as Egan (1970), Gibb (1969), Rogers (1970), and Schutz (1973).

When addressing the topic of leadership self-disclosure Dies and 
Cohen (1976) discuss the complexity involved in studying this issue. These authors note, "The type of phase of group development, content of the verbalization, and personality attributes of the facilitator or therapist moderate the reactions of group members to their leader's personal revelation." These complexities were taken into consideration in the present study. Since the current investigation was conducted within a church setting where relationships between adults and youth are of primary importance, adult leaders self-disclosed according to their own natural style of communication. A more detailed discussion of this will follow.

Having discussed self-disclosure in group interaction in terms of reciprocity and facilitator self-disclosure, consideration will now be given to studies involving self-disclosure as it relates specifically to group intimacy and cohesion. To begin, Silverman (1979) explored the separate effects of three kinds of disclosure activities on the development of intimacy in small groups. His subjects were randomly assigned to three groups structured to share specific information about themselves. They included: 1) The History-Values Group, 2) The Non-verbăl Group, and 3) The Here and Now Group. The results of his study showed that the Here and Now Group changed in attitude toward more intimacy. The other two groups did not change significantly in intimacy. He concluded that groups can be trained to become more intimate attitudinally and verbally through all the methods, but most powerfully through the use of "Direct Communication" with the Here and Now emphasis. of particular importance is that the results of his study seemed to suggest the possibility that certain conditions placed on communication will facilitate or inhibit the intimacy experienced in the group. 
Another study providing foundation for the present investigation was conducted by Kirshner (1976). He set out to investigate the effects of experimental manipulation of self-disclosure on group cohesion. The study was executed within eight hour, interpersonal growth groups. Eight groups of adults met for one eight hour extended session each. Four groups were in high self-disclosing conditions, and four were in low conditions. The groups were conducted by audio taped instructions via a tape recorder operated by group members. Tapes were identical for both conditions, differing only in the instructions and examples relating to self-disclosing behavior. In the high condition examples were designed to elicit highly personal self-disclosures while in the low condition, examples were designed to elicit self-disclosures that were relatively public and non-personal. Results of Kirshner's study showed that high self-disclosure within the group effected more group cohesion than low self-disclosure. In addition, both self-disclosure and group cohesiveness increased over time although they did not follow the same pattern. Self-disclosure increased at a greater rate in the low disclosing condition since the high group had no margin to increase in self-disclosure, and cohesiveness increased at a greater rate in the high condition.

Kirshner's investigation provided data which seemed to suggest that high amounts of self-disclosure within the small group setting directly relates to greater group cohesion. One drawback of Kirshner's study was his use of one eight hour session as opposed to several shorter sessions over a period of time. His methódology did not include a possibility for future interactions between the subjects. This may have affected the amount of disclosure reciprocated. Another drawback 
was the way the conditions for the group sessions were designed. Kirshner's (1976) study provided data on the effects of high and low self-disclosure in a laboratory setting, however the same study conducted in a natural group setting might provide more applicable results.

Given these considerations, the present study was conducted for the purpose of discovering the effects of self-disclosing communication by group members on the overall attraction-to-group among members. This investigation was carried out with ten adolescent groups which met for $\frac{1}{2}$ hour a week for six consecutive weeks. This allowed for continued interaction among subjects over a period of time in a natural setting outside the laboratory, which is an improvement over Kirshner's (1976) design with respect to longitudinal group membership and expectation of future interactions. The writer investigated frequency of selfdisclosure in relation to member's attraction-to-group with the intention of finding results that would be useful to her as a facilitator in groups both inside and outside controlled settings.

Several other variables involved in the social exchange process and linked to self-disclosure demand consideration, the first of which is personality characteristics.

Personality Characteristics and Self-Disclosure

Despite the great amount of research that has been devoted to identifying the personality characteristics determinant of self-disclosure, few reliable relationships have emerged. Cosby (1973) discussed correlations between self-disclosure and personality measures such as Femininity, Authoritarianism, Sociability and Extroversion, Interper- 
sonal Trust and College Achievement. His (Cosby, 1973) review demonstrated low correlations and contradictory results, aside from an apparent positive relationship between disclosure and extraversion. The trends that emerged from this study were neither stable nor strong enough to make accurate predictions in individual cases.

However, when viewing high discloser/low discloser as a personality characteristic it has been repeatedly demonstrated that self-report measures of subject's self-disclosure to best friends were reliably stable predictors of self-disclosures to other persons in both natural and laboratory interaction situations (Altman and Hawthorn, 1966; Taylor, 1968). Subjects categorized as high disclosers to their best friends were found to disclose more to other persons than subjects designated as low-disclosers.

Another study by Altman and Taylor (1973) showed a relationship between a person's ability to self-disclose, which was viewed as a personality trait, and that person's adjustment in a socially isolated environment. Results revealed that low-disclosers who "over-disclosed" to an isolation partner and high disclosers who "under-disclosed" to the partner both had higher failure rates in completing the mission than confederates whose disclosure patterns to an isolation partner conformed to a baseline measure of the subject's level of disclosure to a best friend. Perhaps the low disclosers who "over disclosed" felt reluctant, embarrassed and self-conscious when reflecting on what they had revealed. The discomfort of this may have been the catalyst for quitting the experiment.

Although the above studies have shown some correlation between self-disclosure and personality characteristics, the experimenters 
(Altman and Taylor, 1973) themselves argued that it is unrealistic to expect a discovery of specific trait-disclosure characteristics. With this idea in mind let's consider some of the social situations that are pertinent to the study of self-disclosure.

\section{Social Situation and Self-Disclosure}

An important aspect influencing self-disclosure involves the environmental or situational effects of interpersonal relationships. Taylor (1968) investigated these effects by studying social penetration among college roommates, and experimentally isolated pair"s of men (Altman and Hawthorn, 1966; Taylor and Altman, 1966). In both studies it was noted that self-disclosure occurred at extremely rapid rates, and the subjects exhibited levels of self-disclosure over the eightday isolation period comparable to those achieved by close friends over a period of years. Taylor's (1968) study on roommates provided further weight to these findings. Thus, it is apparent that environment and social-situational variables influence relationship development and disclosure levels.

As can be seen in the literature, social situation plays an important role in self-disclosure studies. Another important aspect to consider is the relationship between self-disclosure and liking and attraction.

Liking and Attraction and Self-Disclosure

Studies linking self-disclosure to liking and attraction have generally been conducted in the context of a basic question: Does disclosure to another lead to liking for that person? or Does liking a person precede disclosure to that person? 
An early experimental test of the correlation between liking and disclosure was conducted by Worthy, Gary, and Kahn (1969). These investigators used groups of 4 women sending written disclosures to each other. Subjects initially were allowed to get acquainted during a preexperimental session, during which they completed an attraction questionaire. Results indicated highly intimate disclosures were made more to those whom they had liked most initially. A questionaire filled out at the end of the experiment showed that liking was greater for those who had made more intimate disclosures. Thus the disclosure liking hypothesis: 1iking leads to disclosure and/or disclosure leads to liking, was confirmed. Certner (1971) confirmed these findings with male and female subjects.

Liking was also correlated with self-disclosure in several studies by Jourard (1971). He found high correlations of the two variables among females, but not among males. The results were discussed in relation to the varied role expectations society has of men and women. Thus, it is likely that women with a sensitive and emotional make-up would self-disclose more than men who are more typically strong, silent and less expressive.

In addition to liking being linked to self-disclosure, physical attraction has also been documented as a positive correlate of selfdisclosure. One investigator (Lefkowitz, 1970) studied the relative influence of physical attractiveness and self-disclosure on cross-sexual liking. Lefkowitz (1970) had female students rate hypothetical first dates. The dating targets varied on three levels of physical attractiveness and five levels of disclosure. Results indicated that physical attractiveness was about three times more important than disclosure in 
accounting for liking and desirability to date. However, the amount of disclosure related more significantly than attractiveness to ratings of "honest," "intellectual" and "interesting." These findings suggested that levels of relationship may play an important mediating role in the link between self-disclosure and liking and attraction.

An additional study showed a correlation between different levels of self-disclosure and liking and attraction. Lange (1981) conducted a study of the effects of low, moderate, and high self-disclosure on subjects during an initial heterosexual encounter. Each subject was introduced to three opposite-sexed confederates, one at a time, who disclosed for 1 minute, either low, moderate, or highly intimate information. Subjects were then asked which "stranger" they would like to meet with again for continued interaction. Results indicated that while activation is pleasant at particular points of intensity, too much or too little disclosure will cause a person to dislike the encounter and withdraw from the stimulus or disclosing individual. The results also indicated that in an initial heterosexual encounter, moderate disclosers were most attractive to test subjects for further interaction (Lange, 1981).

With such a strong link seen in the literature between disclosure and liking and attraction, it is possible to assume that the implications of the above studies could shed light on the heterosexual small group process. Perhaps the more a person likes a small group or the more he or she is attracted to the small group, the more that person will self-disclose. Of particular interest to this investigator is whether or not greater disclosures will lead to greater attraction in the group setting. If Lange's (1981) results were generalizable for 
the small group process, it could be speculated that moderate disclosing communication would create the optimum attraction to the group. Attention will now shift from the variables liking and attraction to psychotherapy and self-disclosure.

Psychotherapy and Self-Disclosure

The section to follow will consider self-disclosure in the context of therapist-client relationships. The experimenter, therapist and interviewer all seek to elicit personal information about another's private life. Studies done in this area provide practical implications for therapy outcome and experimental results.

According to Doster and Nesbitt (1979) the theoretical relationship between self-disclosure and psychotherapy has been examined within four general therapeutic models: the fulfillment model, the ambiguity-reduction model, the interaction model, and the social-learning model. Their explanation follows:

The fulfillment model views self-disclosure as an important intrapersonal and interpersonal process through which individuals can fulfill their personal and interpersonal potentials. Since self-disclosure is a major component of the 'talking therapies,' the ambitguity - reduction model sees the ability to self-disclose as an important prerequisite enabling individuals to assume their role responsibilities in treatment successfully. The interaction model shifts the focus of attention from the individual and/or situation to the interactional process that occurs between individuals. Finally, the social learning model stresses self-disclosure behaviors in the development of social skills programs designed to enable individuals to intiate and maintain effective interpersonal relationships and to express themselves appropriately in social situations."

The empirical research fitting into the framework of these four theoretical constructs showed a high positive correlation between therapist and client disclosure. Rogers (1961) and Jourard (1964) are among the leading advocates of therapist disclosure and client disclo- 
sures in therapy. Traux and Carkhuff (1965) also reported significant correlations in therapist-client disclosure and showed that level of patient disclosure appears to be a predictor of final case outcome. Jourard and Friedman (1970) showed that interviewers or experimenters who disclose as well as elicit greater disclosure from subjects are rated more positively in general than the experimenter who does not self-disclose. From these findings it would seem that in general people enjoy relationships that foster the giving and receiving of personal information. In a client-therapist relationship it is reasonable to assume that in many cases the client expects to self-disclose in therapy, and that the opportunity to disclose is a major motivation for scheduling the session.

Furthermore, in a study done with preadolescents, Vondracek and Vondracek (1971) reported that 6 th grade children in a clinical setting disclosed more to an adult interviewer who disclosed than to an interviewer who did not disclose. The results of their (Vondracek, et al, 1971) study shed light on the present investigation. It is obvious that different persons will normally disclose at different frequencies and levels in their everyday experience. In a laboratory setting, this variation in facilitator disclosure can be controlled. In a natural setting outside the laboratory, variations in the facilitator's "normal" disclosure levels are difficult to control. Thus, results would be somewhat colored by the varieties of personal communication style each facilitator brought to the adolescent small group. One can assume that those adults who normally disclosed more in everyday life would tend to elicit more disclosure in the group merely through disclosing their own personal experiences. This will be discussed further in chapter III 
when analyzing the results of the present study.

Studies such as those mentioned above concerning the effects of therapist disclosure on client disclosure are pléntiful. However, some objections have been raised regarding therapist disclosure made in a manipulative way in order to elicit client self-disclosure. Polansky (1967) stated that the technique is clinically very sloppy and Vondracek (1971) objected to this technique. Cosby (1973) postulated that the disclosure to certain persons may have an adverse effect on the course of therapy, and that some therapists may feel uncomfortable disclosing and communicate that discomfort to the patient.

Regardless of whether or not self-disclosure is elicited from or freely given by the client, most psychotherapy literature agrees with the notion that client self-disclosure makes an important contribution to the progress of treatment. Much of the research literature on disclosure shows a positive relationship between self-disclosure and the outcome of therapy. The greatest support for a relationship between self-disclosure and psychotherapy outcome appears to occur when treatment involves client-centered therapy rather than psychoanalytic or behavior therapy (Chelune, 1979).

Though significant positive correlations have been found between therapist-client disclosures in one-on-one encounters, fewer investigations have been made on the relationship between client self-disclosure and the outcone of group psychotherapy. Traux and Carkhuff (1965) reported a positive statistical relationship between disclosure and group therapy outcome with hospitalized psychiatric patients, but a negative relationship with institutionalized juvenile delinquents. Another study by Vosen (1979) focused on the relationship between 
self-disclosure and changes in self-esteem for participants in an intensive sensitivity training workshop. The workshop was designed to improve interpersonal effectiveness and personal growth. Based on self-ratings, high self-disclosers maintained self-esteem over the course of the group, whereas low-disclosers experienced a reduction in self-esteem. A more recent study by Strassberg, Roback, Anchor, and Abramowitz (1975) reported that schizophrenic patients who were more self-revealing made less therapeutic progress than their counterparts who divulged less personal material. They (Strassberg, et a1. 1975) speculated that the results could be attributed to the limited ability of psychotic persons to integrate social feedback.

Psychotherapy literature dealing with self-disclosure seems to suggest that higher levels of self-disclosure in terms of intimacy and frequency during psychotherapy are positively related to successful therapy outcome. However, the evidence also suggests that this generalization cannot be applied with equal confidence for group therapy approaches. This uncertainty is also reflected in the question being considered: To what extent does self-disćlosure in a group setting effect successful attraction of the members to the group? Having considered sëlf-disclosure in relation to group interaction, personality characteristics, sociál situation, liking and attraction, and psychotherapy, one final variable related to self-disclosure will now be discussed.

Self-disclosure over Time

Social penetration theory (Taylor, Altman, and Sorrentino, 1969) offers one approach to viewing the variable of time and self-disclosure. 
Self-disclosure is pläced within the context of exchange. The theory of social penetration describes the development of interpersonal relationships as a multilevel behavioral process involving verbal and non-verbal exchanges (Taylor, et al. 1969). This discussion is limited to verbal exchanges only. Specifically, the authors (Taylor, et al. 1969) postulate that relationship formation proceeds gradually and in orderly fashion from non-intimate to intimate areas of the self. The most significant feature of this developmental process is the mutual exchange of verbal disclosures that can be assessed in terms of their quantity (breadth) and quality (depth). The time is emphasized as an important factor in the exchange process. In short, it has been shown that self-disclosure increases in both frequency and intimacy, gradually over time. This point is further emphasized in the following paragraph. Based on social penetration theory, Taylor (1968) administered a self-disclosure questionaire to male freshman roommates after they had known each other for $1,3,6,9$, and 13 weeks. According to Taylor's categorization of subjects, half of the roomate pairs were high revealers, while the other half were low revealers. At all points in time the high-revealing dyads reported more mutual disclosure than did the low revealing dyads, although the rate of the increase over time was approximately the same for both groups. There was a rapid increase in non-intimate disclosure, and a slow, gradual increase in intimate disclosures over time. Both groups also showed a significant decrease in liking over time, and this trend was more pronounced among high revealers. The results were of particular interest to this investigator as a focal point of the present study was to discover whether or not frequencies of self-disclosure increased over a six weeks time period. 
Time patterns within groups have also been a focus in empirical research and two studies in this area are worth noting. Taylor and others (1969) found that favorable reward/cost groups showed a greater increase in duration of time talked over four 45-minute interaction periods than did negative reward/cost groups. Berberich, Gabel, and Anchor. (1979) compared the temporal patterns of three different types of group interactions with those in a dyadic session. Three types of parent groups were studies: behavioral, reflective, and discussion groups. The groups differed in content and structure. The behavioral group was given a didactic lecture series with about half of the time allotted for mutual interaction around issues germaine to the content of the lectures. The reflective group was given a series of mini-lectures with at least three-fourths of the time alloted for interactions around pertinent issues. The discussion group was conducted so as to identify major issues as they emerged from the free discussion of parents themselves. The leader in the group served as a facilitator and did not lecture to the group.

Berberich, Gabel, and Anchor's (1979) study reflected some interesting results. The discussion group showed a rise in disclosure as a function of time interaction. However, in the dyadic session the amount of disclosure increased only until the 3rd quarter, then declined. In the reflective group, the amount of self-disclosure was evenly distributed across time. The behavioral group showed a significant drop in self-disclosure during the middle quarters. The author's explanation for this occurrence was that some days the members and the instructor had a more difficult time "settling in" so that discussion could begin. Results of this study provided part of the basis from which the present 
study was developed. Of interest to the present researcher was whether or not the discussion group setting with adolescents would produce results similar to Berberich's (1979) study. That is, would there be a rise in disclosure as a function of time interaction in the adolescent discussion group?

To this point, the chapter has focused on the definition of self-disclosure and on some of the relevant variables associated with it. Attention will now be given to the measurement of self-disclosure, summary remarks, and applications to the present study.

Measurement of Self-disclosure

There are methodological problems and issues inherent in attempting to translate a behavior such as self-disclosure into quantifiable operational terms. Because of the complexity of self-disclosure as a "real life" phenomenon, this was not an easy task for the researcher. This portion of the chapter focuses on the various choices available for assessing self-disclosure. It is clear from a review of selfdisclosure measurement that "for better or worse, self-disclosure when empirically defined, is simply whatever the assessment device measures" (Chelune, 1979).

In an extensive review of self-disclosure literature, Cosby (1973) noted that self-disclosure has been conceptually referred to as both a personality construct and a process variable that occurs during interpersonal interactions. Early research focused largely on selfdisclosure as a correlate associated with personality characteristics. Typically used was Jourard's (1964) Self-Disclosure Questionaire (JSDQ) or one of its variations as the assessment device. Jourard's (1958) initial instrument consisted of 60 items - 10 items in each of six 
content areas: attitudes and opinions, tastes and interests, work or studies, money, personality and body. In this instrument, subjects responded to given items, indicating the extent to which the information had been revealed to four target persons: mother, father, best opposite-sex friend, and best same-sexed friend. Items were scored as 0 - no disclosure to the target person, I - disclosure only in general terms, and 2 - full and complete disclosure about the item (Jourard and Lasakow, 1958). Jourard (1971) later developed a shorter version of the instrument with 25 scoreable items.

Chelune (1979) criticized research aimed at studying self-disclosure as a personality construct, saying its methodological paradigm presupposes that individuals have relatively stable patterns of selfdisclosure across situations. Such a paradigm minimizes the effects of social-situational variables and assumes that current dispositions to disclose can be predicted on the basis of measures such as the JSDQ that assess past disclosures. Other critics (Altman and Taylor, 1973; Cosby, 1973) have suggested that the search for specific personality constructs characteristic of self-disclosure is probably unrealistic and that self-disclosure should be examined in the context of specific relationships and settings, using systematic and behavioral assessment techniques. Chelune (1979) noted that while interest in self-disclosure as a personality constuct has diminished, two findings did emerge from that research: the "reciprocity effect" and the "liking effect." These findings stimulated interest in self-disclosure as a process variable in interpersonal relationships (Chelune, 1979). A brief look at self-disclosure as a process variable of interpersonal behavior will bring further clarity to the understanding of the present study. 
As an interpersonal behavior, self-disclosure is thought to include, at a minimum, five basic characteristics: (1) amount or breadth of personal information disclosed, (2) intimacy of the information revealed (3) duration or rate of disclosure, (4) affective manner of presentation, and (5) self-disclosure flexibility (Chelune, 1979). Researchers are rarely able to examine and measure all five dimensions in a single study and typically elect to use assessment techniques measuring one to two parameters of self-disclosure. Thus, generalizations are limited to the characteristics considered, and self-disclosure is defined by whatever the assessment device measures.

Cosby (1973) discussed the usefulness of distinguishing between breadth and depth in the measurement of self-disclosure as an interpersonal behavior. Breadth typically refers to the range of material an individual chooses to reveal. Depth generally refers to the intimacy of the material revealed; personal material that an individual would share with relatively few people can be regarded as more intimate than material an individual would willingly and unhesitatingly share with nearly anyone regardless of the setting. When someone chooses to share highly intimate material, he or she may be said to be engaging in deeper self-disclosure. At this point it is helpful to note scaling apparatus available to the investigator for measuring depth of self-disclosure, as the present study's methodology necessitated this assessment.

A rather extensive scaling of stimuli for intimacy of communicated statements has been reported by Taylor and Altman (1966). They presented a large number of statements about various aspects of the self, that have been scaled for intimacy, using both college students and military personnel as raters. The communication items used for scaling included 
material from virtually all important areas of an individual's life including religion, marriage and family, love and sex, property and money, and emotions. The data presented by these authors included means and standard deviations based on a Thurstone-type procedure (Taylor and Altman, 1966).

Strassberg and Anchor (1975) rescaled the 677 statements on the ten point Taylor and Altman inventory mentioned above to a three point system. In general this resulted in the division of items into low, middle and high communication intimacy values based on the mean scores for the college student sample. The rescaled items were then inspected to detect similarities in content so that the number of items might be reduced by generating fewer, but more inclusive categories. At completion, the scale consisted of 35 categories approximately evenly divided among the 3 scale values.

Twenty-one varied personal statements were then rated by Strassberg and Anchor using the Intimacy Rating Scale. These statements were presented to 62 college students ( 11 male, 51 female), who were asked to rate the intimacy of each statement according to the following system: (a) non-intimate, information that people would probably be willing to share with someone they did not know well; (b) moderately intimate, information that people would probably share only with someone with whom they were fairly close and;(c) highly intimate, material that people would communicate only to one of their closest friends. The mean intimacy score for each of the 20 statements was then correlated with the ratings for these items established earlier by the authors using the Intimacy Rating Scale. The Pearson product-moment correlation was +.96 . This high correspondence between the ratings 
of intimacy derived from the scale and the ratings by students indicated support for the consensual validity of the Intimacy Rating Scale (IRS) (Strassberg, et a.1. 1975).

Objective techniques, such as the IRS (Strassberg, et al. 1975) for assessing self-disclosure in social interactions usually involve some form of content analysis procedure. This procedure typically divides verbal behavior into units, assigns each unit to a category or position on a metric, and sumnarizes the coded units to provide a basis for inferential statements. Amount or frequency and duration of disclosure are two parameters that lend themselves to this kind of objective measurement (Chelune, 1979). For this reason, the present study used the IRS to determine frequency of self-disclosure in the small group settings.

Summary

Most of the earlier studies on self-disclosure focused on individual difference variables and viewed disclosure conceptually as a personality construct. With the rise and popularity of social learning theory and behavioral approaches to human action, the focus of research on self-disclosure as a personality construct began to move to the examination of social-situational conditions that influence behavior across individuals. Studies focusing on self-disclosure as a personality construct often produced results that were confusing and contradictory. As stated earlier, self-disclosure came to mean whatever the assessment device tested. However, one empirical finding that emerged with a marked degree of consistency was that self-disclosure does not occur capriciously. That is, self-disclosure apparently serves to stimulate further self-disclosure. This reciprocity is found in both 
dyadic encounters as well as in the small group setting.

In the literature reviewed, most studies dealt with variables that had an effect on self-disclosure. Few experiments have been conducted which focus on the effect that self-disclosure has on other variables, such as attraction-to-group. Those that do exist were carried out primarily in dyadic encounters rather than in small group settings as in the current study.

Research on psychotherapy and self-disclosure suggests that higher levels of disclosure during therapy effect a successful outcome. However, the evidence also suggests that this generalization may not necessarily be applied with equal confidence to group therapy. Results from the present study should diminish in part some of the uncertainty surrounding this group phenomenon. Though studies are few in number with respect to the effect of self-disclosure on group process, there is widespread agreement that self-disclosure is a crucial variable in comunication both in a dyadic and group encounter.

\section{Applications to the present study}

The theoretical background of self-disclosure delineated above provided the foundation for the current study. Several specific applications can be made at this point. The applications to be considered follow:

1. Self-disclosure studies are plentiful, however there are few investigations conducted within the small group setting. For this reason the present study seeks to discover how self-disclosure effects small group process.

2. The studies which have investigated self-disclosure in small groups have used adults as subjects. None of the studies that were available 
to this researcher incorporated adolescents in the small group

formation. The present investigation is designed to test one specific population, senior high students ages 15-18.

3. Many of the studies dealing with the effect of self-disclosure on other variables have been done within one limited time period. That is, dyads or groups met for one several hour session, or for a long weekend. The present study has been designed to incorporate a longer testing time involving six consecutive weeks. This should allow more "natural" disclosure to occur over time, rather than forcing quick disclosures.

4. Research available to this investigator dealing with self-disclosure was conducted inside a laboratory setting. For the purposes of this study, all testing was done outside the laboratory, in a natural social gathering. Results gained should be useful for application and training within the natural setting.

5. Several formats of group discussion were mentioned in the theoretical background section. The present study used the discussion-group format for interaction rather than the reflective or behavioral-group format. This type of structure for interaction had been previously used for small groups in the youth department and seemed most conducive to adolescent discussions.

6. Facilitator disclosure was shown to be a controversial issue. Since the current study was conducted within a church setting where relationships between adults and youth are of primary importance, adult facilitators self-disclosed according to their own natural style of communication. They were instructed not to act strictly as managers of group process, but to interact with the young people in the 
small group the same way they interacted outside the small group.

7. A review of the literature revealed that there are inconsistencies in conceptual definitions used in self-disclosure studies. To the extent that each operationally defines a somewhat different subset of self-disclosing behaviors, different methods and assessment strategies become necessary. In the present study, the scope of empirical inquiry of self-revelations was limited to onlv those disclosures that were communicated in speaking to one another. Cosby's (1973) definition of self-disclosure, any information person A verbally communicates to person $B$, was used as the basis for the assessment of self-disclosure. Using this definition, self-disclosure statements by subjects in the present study met the following three operational criteria: (I) They contained personal information about person A; (2) Person A verbally communicated this information; and (3) Person A communicated this information to Person B or to the group. This definition was chosen over others mentioned in the literature because it was compatible with the assessment devices avallable to the researcher (cf. Chapter Two).

The applications above serve as a rationale for the methods and procedures delineated in Chapter Two. Having reviewed the theoretical background of self-disclosure, attention will now be given to the theoretical background of attraction-to-group. The discussion that follows will focus on how the concept is defined, it's measurement, and applications to the present study.

\section{ATTRACTION-TO-GROUP}

Definition and Usages

The group process literature revealed that the concept attraction- 
to-group was often embedded in research concerning group "cohesion," and in some instances the two terms were used interchangeably. Not only did this confound the meaning of attraction-to-group and cohesion, but it also made clean measurement of either concept as an independent variable a difficult task. Clearly, attraction-to-group must be defined and differentiated from group cohesion.

The concept of group cohesion commonly encompasses such ideas as "group pride," "group solidarity," "group loyalty," "team spirit," and "team work." These terms have been used in both popular and scientific literature concerned with the essential idea of "groupness" in human relations (Johnson and Johnson, 1975; Kirshner, 1976; Hare 1976). The diverse meanings of the terms are exemplified by the several operational definitions that have been used, such as the relative frequency of "we" versus "I" references in conversation (Cartwright, 1968); the relative frequency of friendship choices within and outside the group (Egan, 1970); the degree to which norms are shared (Johnson and Johnson, 1975); the strength of desire to continue relations as a group, and the perception of the group being better than others in various respects (Seashore, 1954).

Cartwright and Zander (1960) distinguished three different and commonly used meanings of the term cohesion: "...a. attraction to the group including resistance to leaving it; $b$. morale, or the level of motivation of the members to attack their tasks with zeal; and c. coordination of the efforts of members." They held that these three categories of meanings are conceptually different, susceptible to independent measurement, and should be kept separate for reasons of conceptual clarity. Cartwright and Zander (1960) proposed that the term "cohesive- 
ness" be used only in reference to the attraction of group members to the group.

Evans and Jarvis (1980) proposed that investigators should view "cohesiveness" and "attraction-to-group" as separate variables in group process. They (Evans, et al. 1980) defined "cohesion" as the degree of unification of the group field. An operational definition for cohesion might include similarity among group members in their perception of events and perhaps a bonding together in response to the outside world (Evans, et a1. 1980). On the other hand they defined (Evans, et a1. 1980) "attraction-to-group" as being an individual's desire to identify with and be an accepted member of the group. This definition relates directly to the members' attitude toward the group rather than requiring specifications of the reasons for his or her feelings (Evans, et al. 1980). This will be discussed further in the Theoretical Developrent section of this chapter.

In the present study, "attraction-to-group" was defined in the fashion recommended by Evans and Jarvis (1980): namely as the individual's desire to identify with and to be an accepted member of the group. This definition differs from "cohesion" in that emphasis in the former is placed on individual phenomena in the group rather than on group phenomena. In this study, a group was said to have a high degree of attraction-to-group if the members: 1) perceived themselves to be a part of the group 2) preferred to remain in the group rather than to leave, and 3) perceived their group to be better than other groups with respect to the way members got along together.

In the discussion to follow, theoretical explication and a sampling of the research involving these variables is reviewed in greater detail. 
Attention is given first to the theoretical development of cohesion and attraction-to-group and second to the measurement of these variables.

\section{Theoretical Development}

The concept of cohesion/attraction-to-group has played a major role in group dynamics and group therapy research during the past several decades. Investigators have cited cohesion as a contributing factor to various group processes, including conformity (Back, 1951; Festinger, 1950; Gerard, 1951), productivity (Goodacre, 1953; Seashore, 1954) and behavior change (Bednar and Lawlis, 1971). "Reduction of anxiety" for group members was found by Lewin (1939) to be an effect of group cohesion, and Cartwright (1968) related cohesion to the maintenance of group membership. Further importance was placed on cohesion in task groups (Cartwright, 1968), therapeutic groups (Bednar and Lawlis, 1971) and work units (Seashore, 1954).

In spite of the importance placed on the concept of cohesion, a lack of clarity has characterized both its definition and its measurement. Cohesion has been uniformly recognized as a group phenomenon, yet its measurement generally involves measuring the levels of attraction expressed by individual group members and averaging them (Cartwright, 1968). Thus, cohesion has been considered in the literature as the sum of individual members' attraction-to-group scores.

Leon Festinger (1950) conducted one of the earliest systematic works on social communication which included a focus on group cohesion. He and his associates at the Research Center for Group Dynamics at the University of Michigan introduced the first widely accepted definition of cohesion: "the total field of forces which acts on members to remain in the group" (Festinger, 1950). In principle, this definition 
requires that the investigator identify all of the forces which might cause a member to continue group membership and then measure these factors and combine them in some way. However, the Michigan researchers operationalized cohesion by measuring the members' decision to remain in the group through an index of friendship or attraction to group.

Gross and Martin (1952) criticized the operational definition used by the Michigan researchers and contended that not all the variables included in their definition of "the total field of forces" were adequately measured. They (Gross and Martin, 1952) presented an alternative conception of cohesion: "The resistance of a group to disruptive forces," but did not present a plan for making their definition operational. Back (1951) defined "cohesion" as the attraction which a group has for its members and Back equated this definition with Festinger's definition. Libo (1953) argued that both of these definitions were too general and criticized Gross and Martin (1952) for attacking the measurement procedures of Festinger (1950) without presenting an alternative or better method.

Libo (1953) offered further theoretical refinement of cohesion and attraction-to-group. He was the first to make a distinction between cohesion, "The group's attraction for its members," and attraction-togroup, "the resultant of forces acting on each member to remain in the group." Libo (1953) argued that: "Cohesion depends on the imprecise method of combining individual attraction-to-group scores into a total group value." He (Libo, 1953) contended that the individual construct, attraction-to-group, may arise from a number of group characteristics such as group goals, activities, prestige, attraction to other members and opportunity for free emotional expression, and that it may also 
arise from external pressure. He also argued that the best measure of attraction-to-group is whether a member chooses to stay in the group when forced to make a choice. Based on this theoretical foundation, he developed a projective test of degrees of group cohesiveness in terms of attraction-to-group.

VanBergen and Koekebakker (1959), two Dutch researchers, also suggested that attraction-to-group and cohesion be considered as separate concepts, with cohesion referring to "the degree of unification of the group field." They found attraction-to-group to be a more useful concept for their purposes, and assessed attraction in terms of the members' resistance to leave the group.

About the same period, Cartwright and Zander (1960) indicated that a major question concerning cohesion was how to combine several individual scores of attraction-to-group to form a single value of cohesiveness. They did not concur with VanBergen and Koekebakker's suggestions that cohesion be considered something different from a combination of attraction-to-group scores.

In an extensive review of the literature and the theoretical issues involved in cohesion, Cartwright (1968) examined the approaches which have been used to measure this notion. He noted that the combination of individual scores to form an index of cohesion is a major measurement problem and concluded that: "A standard all purpose procedure for measuring group cohesion does not yet exist" (Cartwright, 1968).

More recently, attention has been given to group cohesion in therapeutic sessions. Bednar and Lawlis (1971) stressed personal acceptance in conceptualizing cohesion, arguing that: 
The concept of 'cohesion' in group psychotherapy is among the most discussed and least researched variables. Though the word is used extensively, and defined often, a truly satisfactory operational definition has yet to be adopted. Cohesion is usually defined as interpersonal trust, attraction, and involvement.

It is evident from this brief review that despite the amount of attention given to group cohesion, the concept still remains unclear. Some researchers have chosen to conceptualize it as the averaged sum of individual members' attraction-to-group (Festinger, 1950; Gross and Martin, 1952; Back, 1951), while others have chosen to distinguish between cohesion and attraction-to-group (Libo, 1953: Vanßergen, et al. 1959; Evan, et al. 1980). It is apparent from earlier research that a variety of factors enter into the development of cohesion and attraction-to-group in the small group setting. At this point attention will be turned from the theoretical development of cohesion and attraction-to-group to the measurement of these variables as found in the literature.

Measurement of Group Cohesion

As Cartwright (1968) pointed out, the lack of an agreed upon nominal definition of cohesion and attraction-to-group has led to a wide variety of measurement techniques. When researchers use different definitions and measurement procedures, it becomes extremely difficult to compare their results in meaningful ways. It is also more difficult for future scholars to build on previous research. The following paragraphs delineate some of the various methods and techniques used to measure attraction-to-group/cohesion in relation to the conceptual and operational definitions.

In order to measure cohesion, Festinger (1950) and Back (1951) 
used the comparative number of friendship ties existing among members within different groups. The attractiveness of the group was measured in yet another way by Schachter (1951), who in a laboratory setting asked subjects if they wanted to remain as members in the newly formed clubs, how often they wanted the group to meet, and whether they wished to ask others to stay in the group.

Stanley Seashore (1954) studied group cohesiveness in industrial work groups, using 228 small formal work units in a plant manufacturing heavy machinery. Five operational measures were utilized, in Seashore's study to determine cohesion. Workers were asked to respond to the following questions: "Do you feel that you are really a part of your work group?," "If you had a chance to do the same kind of work, for the same pay in another work group, how would you feel about moving?" and "How does your work group compare to other work groups at Midwest on each of the following points?--The way the men get along together, the way the men stick together, and the way the men help each other on the job?" According to Miller (1970) the validity of Seashore's measure has been established, for he argued that:

The intercorrelations among mean scale values for the groups, on scales comprising the index of cohesiveness ranged from .15 to .70. The variance found between groups on this scale was significant beyond the .001 level.

It is apparent that Seashore's scale is sensitive enough to discriminate between low and high levels of cohesiveness in various groups.

Kirshner (1976) measured cohesion according to the duration of time a group spent in the "group hug" at the close of a group session. He also used the Gruen Cohesiveness scale, a four item questionaire 
that examined product estimations of group tasks.

In addressing the challenge of effectively measuring cohesion/ attraction-to-group, Evans and Jarvis (1980) referred to an earlier definition of cohesion: "the degree of unification of the group field" (VanBergen, et al. 1959). They (Evans, et al. 1980) postulated that this definition is closer to the group nature of the phenomenon than any other definition, saying that it relates to a closeness among group members, a similarity in perception of events, and perhaps a bonding together in response to the outside world. Using this definition, they concluded that all members of a cohesive group would tend to perceive the group similarly and respond to questions about the group in the same way, leading to a limited range of scores on an assessment device. Furthermore, such an instrument could explore perceptions of the group experience, responses to outsiders, and typical responses of the group to specific situations etc." (Evans, et a1. 1980).

In contrast to cohesion, they (Evans, et al. 1980) asserted that attraction-to-group refers to the individual members' feelings about the group. They defined attraction-to-group to be an "individual's desire to identify with and be an accepted member of the group," arguing that this definition related directly to the members attitude toward the group rather than requiring specification of the reasons for his or her feelings. The operational definition of the concept entails assessment of the individuals' sense of involvement in the group, feelings of acceptance, and desire for continued membership. When reviewing the available measurement techniques, Seashore's Cohesion Measure (1954) was found to be most parallel to the conceptual 
definition of attraction-to-group offered by Evans and Jarvis (1980). Operationally it allowed for an assessment of the individuals' sense of involvement in the group, feelings of acceptance, and desire for continued membership.

Having discussed the definition of attraction-to-group, it's theoretical development and measurement, the following section will include a brief summary of key points mentioned above.

Summary

Research shows that cohesion and attraction-to-group are extremely important factors in group process. However, early studies reported contradictory and of ten confusing results concerning this group phenomenon. Problems arise in the varieties of conceptual and operational definitions devised by experimenters. Recent literature attests to the importance of refining the concepts of cohesion and attraction-to-group and viewing them as two separate variables to be studied in their own right. For the purposes of this study, cohesion is understood as the degree of unification of the group field. An investigation of cohesion in a group might explore perceptions of the group experience, response to outsiders, and typical responses of the group to specific situations. On the other hand, attraction-to-group can be defined as the individual group member's desire to identify with and be an accepted member of the group. An investigation of attraction-to-group might focus on the individual's sense of involvement, feelings of acceptance, and desire for continued membership. Though there is unanimous agreement among group researchers that cohesion and attraction-to-group are primary factors in keeping a group in existence, a standard all-purpose procedure for measuring these concepts 
separately does not yet exist. The present investigation focuses specifically on attraction-to-group and the issue of whether the variable is effected by varying frequencies of self-disclosure.

\section{Applications to the present study}

The theoretical background of attraction-to-group delineated above provided the foundation for the current study. Specific applications can be made at this point. The applications to be considered follow: 1. A lack of clarity has surrounded the definitions of cohesion and attraction-to-group. Recent literature attests to the importance of refining these concepts and viewing them as separate variables to be studied in their own right. Few studies have done this. The present study is therefore designed to study specifically attraction-togroup which is defined as the individual member's desire to identify with and to be an accepted member of the group.

2. The measurement techniques available to this investigator were adequate for the assessment of attraction-to-group as defined in this study. The device used was limited to investigating the individual's sense of involvement, feelings of acceptance, and desire for continued membership which focused on individual phenomena within the small group rather than on group phenomena (cf. Chapter Two).

The theoretical background offered above serves as a rationale for the methods and procedures delineated in the following chapter. 


\section{CHAPTER II}

\section{METHODS AND PROCEDURES}

The present investigation was designed to assess the effects of self-disclosing communication on attraction-to-group response in the small group setting.

\section{Hypotheses}

There were three hypotheses for this study:

Hypothesis 1. Frequency of self-disclosure will increase over time in the small group setting.

Hypothesis 2. A stong positive association will be observed between the initial frequency of self-disclosing communication and the eventual degree of attraction-to-group. That is, higher frequencies of self-disclosure will be followed by greater attraction-to-group.

Hypothesis 3. Self-disclosure and attraction-to-group will co-vary over time, that is: 1 . As self-disclosure increases, attraction-to-group will increase; 2. As self-disclosure decreases, attraction-to-group will decrease; and 3. As self-disclosure fluctuates, there will be a systematic fluctuation in attraction-to-group.

II. Design of the Study

This section focuses on the design of the study to test the above 
hypotheses. Major consideration is given to the subjects in the investigation, group discussion topics, training of adult subjects, and to the training of the self-disclosure co-rater. Each of these are discussed in turn in the following paragraphs.

\section{Subjects}

Small groups were formed from 120 Senior High Students, grades nine through twelve, who regularly attend youth meetings at East Hill Church, Gresham, Oregon. Students names were listed on an alphabetical roster. Individuals were assigned to groups at random, with a constraint that each group would be assigned no more than twelve members. In this way, ten groups with twelve members each were obtained. A group of ten adult leaders who regularly attended youth meetings were assigned to the small groups according to random selection. The groups were mixed in age and sex. Subjects in the ten groups were not informed as to the specific focus of the study. However, they were told that they would be participating in the writer's school project concerning small group communication.

The week prior to the first small group sessions, subjects received a phone call from the adult subject in the group reminding them of the time, date, and place to meet together. The adult subject instructed the youth to be prompt and consistent in meeting with the other members of the small group.

\section{Group Discussion Topics}

The topic of discussion for each group was identical for every group during an evening session. However, topics did vary from week to week. Each group was assigned to discuss the lecture given by the 
Youth Director during the first half-hour of the evening. Weekly discussion was to be centered on three basic questions regardless of the lecture topic. Adult group members asked the following questions during the course of each half hour:

1) What was the main idea John was talking about tonight?

2) Can what you have learned be useful?

3) How might his teaching help you?

\section{Training of Adult Facilitators}

In order to carry out this investigation over a 6 week period, certain steps were taken to help insure the consistency of youth attendance to meetings and adult subjects dependability in administering group attraction measures and taking audio recordings. Prior to the first, second, and third evenings of testing, adult group subjects met with the experimenter for review and instruction of procedures. Suggestions were given for making good quality tapes and for desensitizing the youth to the tape recorders. Group seating and vocal diction and clarity were discussed. In addition, instructions were given concerning how to discuss the youth self-report attraction-togroup measure with their groups. Adolescents were to be informed that the measures were confidential, anonymous and that their honesty was of utmost importance. They were to judge their sessions according to how they perceived the attraction-to-group for that particular evening. If it was low one week and high another, that was acceptable. Honesty was stressed.

Adult members were instructed to call youth members once a week prior to the testing sessions to encourage consistent attendance. Each adult was asked to provide an audio cassette recorder for taping his 
or her small group discussion. The experimenter provided 30 minute tapes for each group session over the six weeks of investigation. In addition to the above instructions, the facilitators were given specific directions concerning their interaction and communication with small group members. Since the present study was conducted within a church setting where relationships between adults and youth were of primary importance, facilitators were advised to disclose according to their own natural style of communication. They were not to act strictly as managers of group process, but were to interact with the young people in the small group the same way they interacted outside the small group. This model of group facilitation was chosen because it best served the purposes of the ongoing ministry of the Youth Department. Personal relationships between adult facilitators and young people were stressed with the assumption that all persons in the discussion group were to "share and share alike." The adults were willing to share their immediate personal experiences as well as various aspects of their lives outside the group, thus serving as a model for spontaneous, genuine, and creative interaction.

Not only were facilitators instructed to disclose according to their own natural style of communication, but they were also directed not to try to manipulate openness in discussion, but to allow a free flow of expression from group members according to their own initiative (cf. Chapter One, pg. 10 ).

\section{Training of Self-Disclosure Co-Rater}

In order to guard against experimenter bias, two judges were used to rate the tapes for self-disclosure. The experimenter was assisted by a confederate who was experienced in the study of communi- 
cations. Five hours of rater training was conducted to insure compatible judgments. Specific focus was placed on content analysis. Instructions were given to rate explicit content and to avoid making interpretations or assumptions about the intention or motivation underlying a response. The IRS provided a methodological framework allowing four possible ratings for any given member statement: level one, level two, level three, or no disclosure. A list of protocols by which the statements were rated is included in the Appendix (cf. pg. 85 ). Figure One gives specific examples of rated statements as categorized in the three disclosure levels. The basis for data analysis was the "statement" taken as a natural unit of actual behavior. It is important to note that a "statement" was recognized as any ratable utterance from beginning to conclusion made by a subject, regardless of length or amount of time taken to deliver it. One group analyst (Anchor, 1970) described such a procedure as a natural unit upon which to base such ratings (cf. pg. 49). This approach focuses primarily on thought units as statements in contrast to other group rating systems which make judgments sentence-by-sentence or according to time segments. For example, spontaneous fragmentary responses such as "Very funny," "So what," and "That's stupid," are all considered ratable utterances along with those thought units which were uttered in complete sentences. Figure 1 lists actual taped statement examples according to their level of disclosure. 


\section{Level One Disclosures}

"I like ice cream."

"We all got out of school for vacation yesterday."

"I'd rather have strawberry lip gloss than peppermint."

"That movie was on T.V. last night and I watched it."

"It's 0.K. with me if you smoke."

"She was at the football game with me."

"I like KPAM best for radio stations."

"It would be neat to be a stunt man."

\section{Leve1 Two Disclosures}

"It bothers me when my friends smoke dope."

"When I lied to my mom she always found out."

"I want to go into the Marines and then go to Hollywood for work."

"When I'm going through struggles it helps when I talk to my friends about it."

"I really like to look at good looking guys."

"Sometimes I don't feel like I'm really a part of the group, especially when my boyfriend takes off and talks with everyone else."

"I like that!"

\section{Level Three Disclosures}

"I was seeing a psychologist for awhile after I took the pills."

"My mom is always getting drunk and I hate it."

"I really love my mom and dad but I get so angry when they make

it hard on me to read my Bible."

"My mom and dad are divorced, and I'm living with my dad, but my mom always makes me feel guilty because I don't live with her."

"I hate him!"

"I know I couldn't do it even if I tried...besides, they would probably laugh at me."

Figure 1. Examples of Rated Statements in the Three Disclosure Levels.

To establish interjudge reliability 402 statements were rated according to the IRS. Reliability test results showed high correlation between the rater's judgments, with $96 \%$ agreement.

\section{PROCEDURES}

This section focuses on the procedures used to carry out the present investigation. Discussion is first given concerning the actual process of small groups gathering together and guidelines for their 
discussion time. This is followed by a delineation of measurement procedures used for data analysis.

\section{The Gathering of Small Groups}

After the small groups were formed by random assignment, subjects of all 10 groups gathered weekly at East Hill Activity Center for the regular mid-week youth meeting. The first hour with all subjects combined was devoted to singing, games, and one-half hour of Bible study. A Bible-teaching was delivered by the Youth Pastor. The last half-hour was devoted to small group meetings.

Upon arrival at the small group, each subject was welcomed and asked to sit in a circle as close as possible to the tape recorder. Adult subjects "played" with the recorder to help desensitize the youth from feeling self-conscious about the recordings. The adult subjects informally explained that the tapes were being made for the experimenter's school project and that they were confidential and would not be revealed to any others. They also told group members that during the last two minutes they would fill out a brief questionnaire concerning how they felt about their small groups.

After "settling-in," the adult member helped focus group discussion by using the 3 standard questions provided by the experimenter. The youth were told that their time together was for the purpose of discussing the teaching they had heard earlier during the youth meeting. The three discussion questions previously mentioned helped to focus group communication ( $\mathrm{cf} . \mathrm{pg} \cdot 44$ ). Each question was answered and discussed according to the desire of the group, i.e. if the group wanted to remain on question "one" they could, and if they wanted to discuss 
all 3 answers, that was acceptable. This gave the groups a freedom of choice for discussion within a basic framework. Discussion continued thirty minutes and during the final 2-3 minutes of the group sessions, the adolescent subjects were asked to complete the attraction-to-group self-report measure. Adult subjects completed a separate attractionto-group measure also (cf pg. 53). All measures were given to the adult subjects, who in turn delivered the tapes and questionnaires to the experimenter at the close of each week's meeting. This procedure continued over six weeks of investigation.

\section{Measurement Procedures}

The study procedures used the correlational technique with frequency of self-disclosure treated as the independent variable and measures of attraction-to-group as the dependent variable. In order to assess frequency of self-disclosure and its effect on small group attraction-to-group, two measures were employed. The independent variable, self-disclosure, was measured according to the StrassbergAnchor Intimacy Rating Scale IRS (cf. pg. 84 ). This system rates the intimacy level of a wide variety of subject areas on a three point ordinal scale. The material scaled in this system includes most aspects of an individual's personal life that might constitute material for self-disclosure. The consensual validity of the IRS was established by 62 college students who rated 22 varied personal statements according to the IRS. The percent of agreement with the author's original rating was computed to be $96 \%$ (cf. pg. 27 ). This suggests a high degree of correspondence between the ratings of intimacy derived from the IRS and the average ratings of college students. In the present study, only statements categorized in levels two and three of the system were used 
in calculating frequency of self-disclosure. A check system was used to tabulate the total number of disclosures from each judge. Since it was not necessary to rate all six weeks of recordings from all ten groups, ratings were made only on tapes of the five groups which had the highest attendance index and least absenteeism. The groups which had the most consistent attendance were groups $2,4,6,7$ and 9 .

In order to measure the frequency of self-disclosure according to the IRS, all small group sessions were audio recorded on tape. Each one-half hour session was divided into ten 3-minute segments. The first of the three minute segments was not rated, as this was considered the "settling-in time" for the groups. The writer decided that since it was neither feasible nor necessary to rate all the taped statements, sample segments were chosen from each tape. Three 3-minute units were rated from each of the recordings. One 3-minute segment was systematically selected from the initial, medial, and final portions of each tape footage. This procedure is identified as a stratified random field. A layout of the stratified random field according to measured tape footage is presented in figure 2.

$\begin{array}{llll}\text { Settling-in time } & \text { Section One } & =000-072 \\ \text { Initial } & \begin{array}{l}\text { Section Two } \\ \text { Section Three }\end{array} & =136-192 \\ & \text { Section Four } & =193-243 \\ & & \\ \text { Medial } & \text { Section Five } & =244-291 \\ & \text { Section Six } & =292-336 \\ & \text { Section Seven } & =337-378 \\ \text { Final } & \text { Section Eight } & =379-418 \\ & \text { Section Nine } & =419-456 \\ & \text { Section Ten } & =457-502\end{array}$

Figure 2. Stratified Random Field 
The dependent variable, attraction-to-group, was measured by using a revised version of Seashore's (cf. pg. 52 ) Attraction-toGroup Measure. The investigation of attraction-to-group assumes that there are measurable differences among, the groups with respect to degree of attraction. The operational definition of attraction-to-group for this investigation has three distinguishable aspects: 1 . identifiable membership in the group, 2. attraction to the group or resistance to leaving, and 3 . perception of the group being better than others in terms of mutual attraction among members. Thus, the variable was defined in such a way that a group was said to have a high degree of attraction-to-group if the members perceived themselves to be a part of the group, preferred to remain in the group rather than leave, and perceived their group to be better than other groups with respect to the way they got along together.

The index of attraction to group was based upon responses to direct questions from Seashore's Measure (cf. pg. 52 ).

The variance found between groups on this scale was significant beyond the .001 level. Intercorrelations among mean scale values for the groups on scales comprising the index of attraction-to-group ranged from .15 to .70 (cf. pg. 38 ). The measure employed is presented in Figure 3. 
REVISED VERSION OF S.E.SEASHORE'S GROUP COHESIVENESS INDEX

(DESIGNED SPECIFICALLY FOR ADOLESCENTS

GRADES 9 - 12)

LET'S THINK ABOUT YOUR SMALL GROUP.....

DO YOU FEEL THAT YOU ARE REALLY A PART OF YOUR SMALL GROUP?

I really feel a part of my small group

I feel included in most ways

I feel included sometimes, but not always

I don't feel like I belong

IF YOU HAD A GHANCE TO DO THE SAME KIND OF ACTIVITIES IN

ANOTHER SMALL GROUP, HOW WOULD YOU FEEL ABOUT SWITCHING

TO ANOTHER GROUP?

I want very much to stay where I am

I would rather stay where $I$ am than move

I would rather move than stay where I am

I want very much to move to a different group

HOW DO YOU THINK THE PEOPLE GET ALONG TOGETHER IN YOUR

SMALL GROUP?

Better than most

About the same as most

Not as good as most

Far worse than most

HOW WELL DO THE PEOPLE IN THE GROUP HELP EACH OTHER IN THE

SMALL GROUP?

Better than most

About the same as most

Not as good as most

Far worse than most

Figure 3.

The measure was administered at the close of each session during the 6 weeks of testing. Each Senior High group member responded according to the way he or she felt about the "attraction-to-group" that particular evening.

A separate self-report measure was given to adult group members. This measured their perception of the member's attraction-to-group on a four point ordinal scale, 4 being the highest level of attraction and 1 being the lowest. This measure is presented in Figure 4. 
ADULT SMALL GROUP MEMBER QUESTIONNATRE

Following tonights session, please rate your group in terms of how "Attracted to the Group" your kids were.

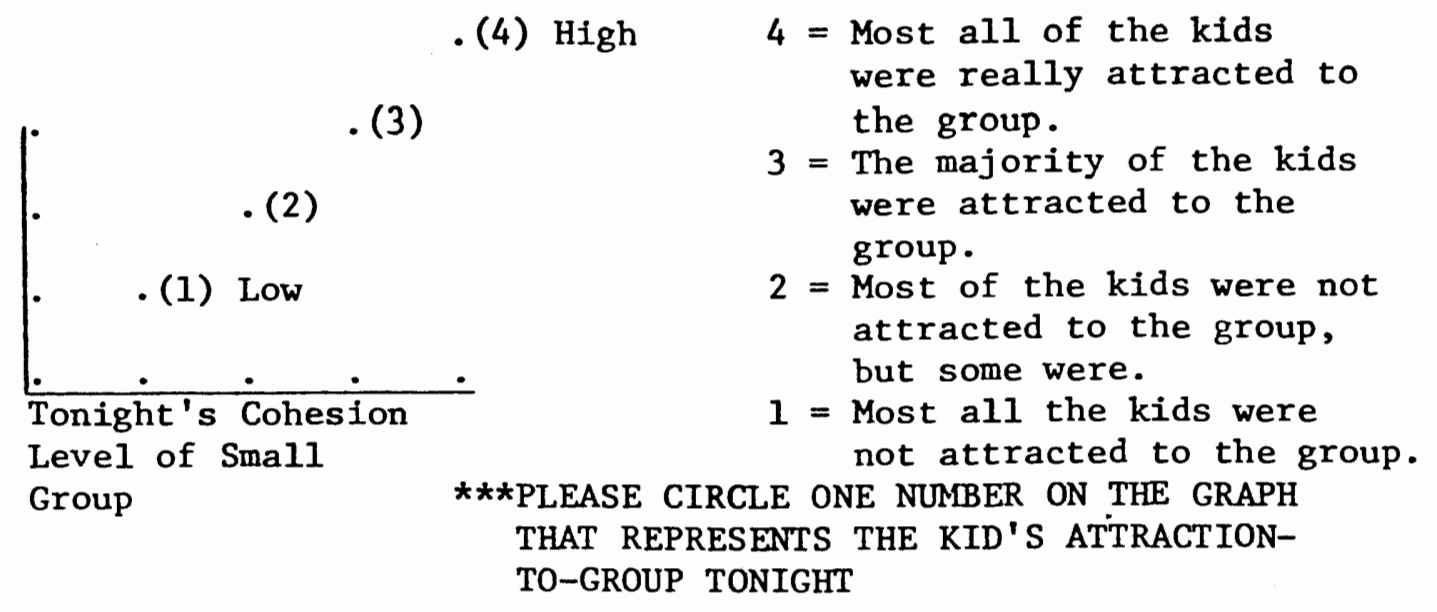

Figure 4.

The above paragraphs cover information regarding the present study's hypotheses, design, and procedures. The following chapter includes the results of the investigation with evaluation where appropriate. 
CHAPTER III

\section{RESULTS AND DISCUSSION}

The results of the study will be presented in order of the three hypotheses and their corresponding measures. Parametric statistic operations (correlations and standard deviations) were performed according to William Mendenhall's (1967) publication.

Hypothesis 1. Frequency of self-disclosure will increase over time in the small group setting.

Self-disclosure was measured according to the IRS (cf. pg. 84 ). This provided a framework for measuring the intimacy level of selfdisclosing statements on a three point ordinal scale. The material scaled in this system included most aspects of an individual's personal life that might constitute material for self-disclosure. Only self-disclosing statements categorized in levels two and three were used to calculate the frequency of self-disclosure. This procedure was followed in order to provide a clean cut-off point of low selfdisclosing statements from medium to high disclosing statements. Of particular importance to this investigator was the frequency of medium to high disclosures made in the small group setting. A simple summation of judge ratings for groups $2,4,6,7$, and 9 was made, and the average of the two scores figured per week, per group. See Table 1. 
TABLE I

\section{FREQUENCY OF SELF-DISCLOSURE}

PER GROUP, PER WEEK

\begin{tabular}{|c|c|c|c|c|c|c|}
\hline Group & $\begin{array}{l}\text { Week } \\
\text { I }\end{array}$ & 2 & 3 & 4 & 5 & 6 \\
\hline Group 2 & 62.4 & 73.5 & 62 & 70.5 & 50.5 & 55.5 \\
\hline Group 4 & 40 & 45 & 49 & 45 & 50 & 41 \\
\hline Group 6 & 38 & 53 & 49 & 71 & 52 & 52 \\
\hline Group 7 & 50 & 42 & 45 & 41 & 42 & 33 \\
\hline Group 9 & 43 & 42.5 & 63.5 & 54 & 52.2 & 58 \\
\hline
\end{tabular}

The above statistics can be portrayed graphically as seen in

Figure 5.

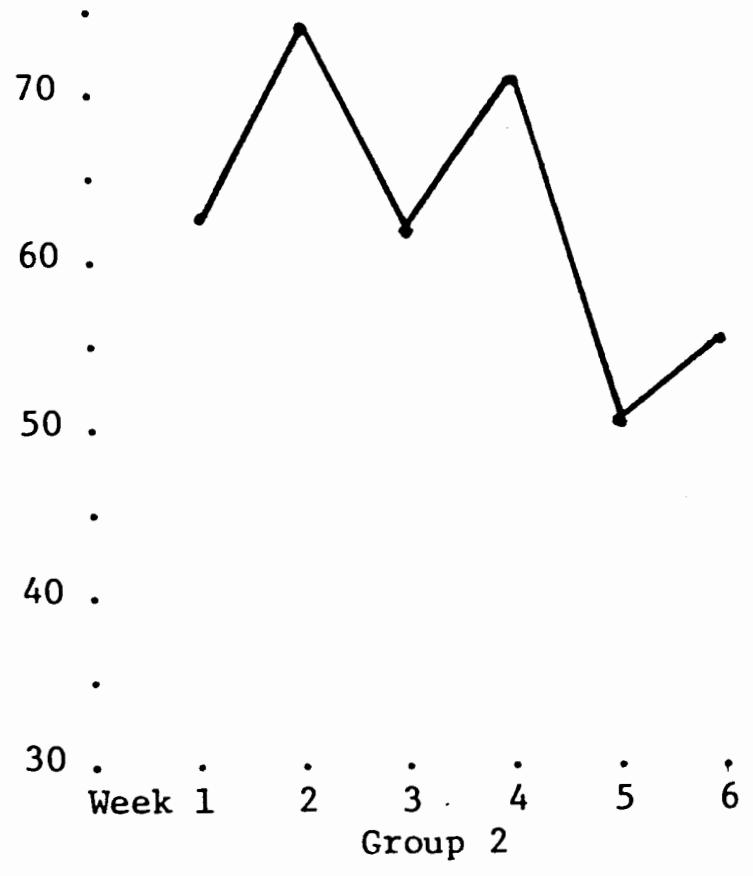




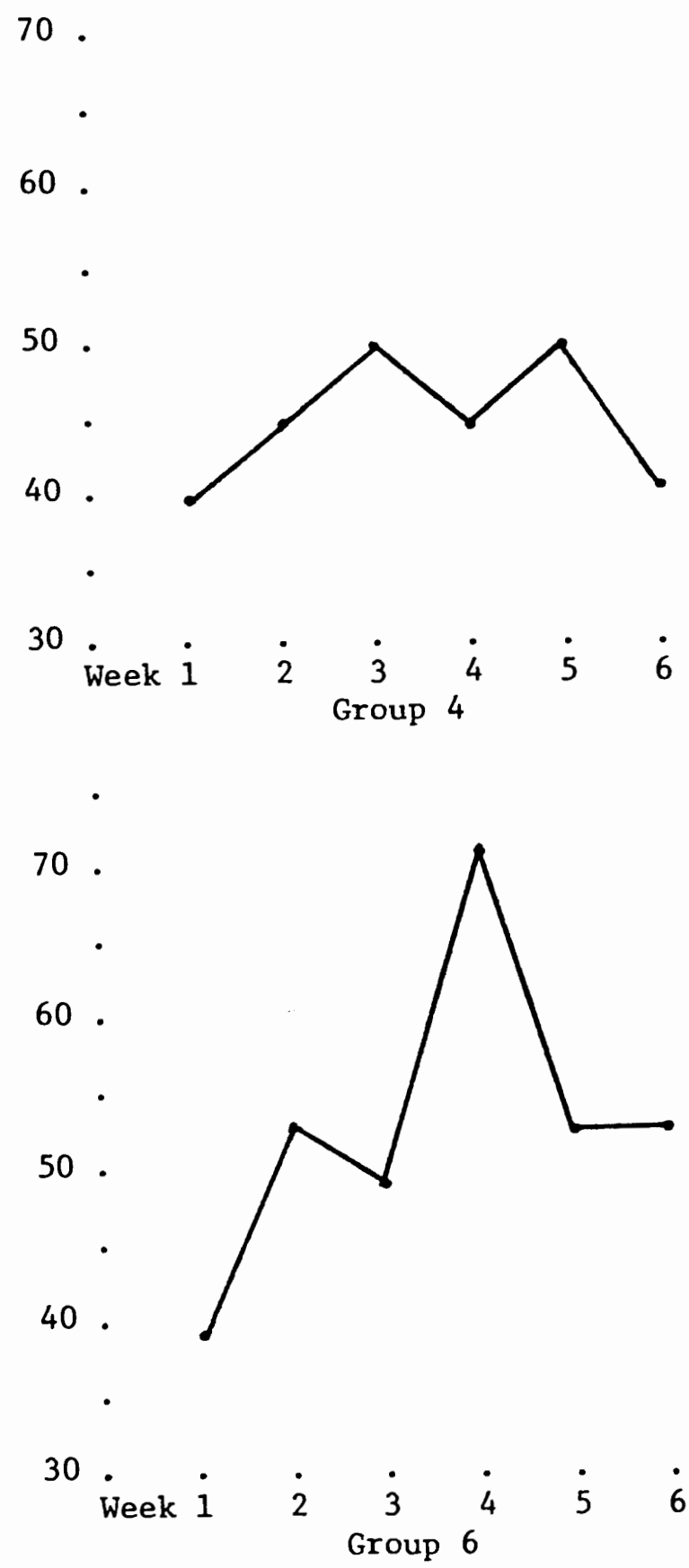




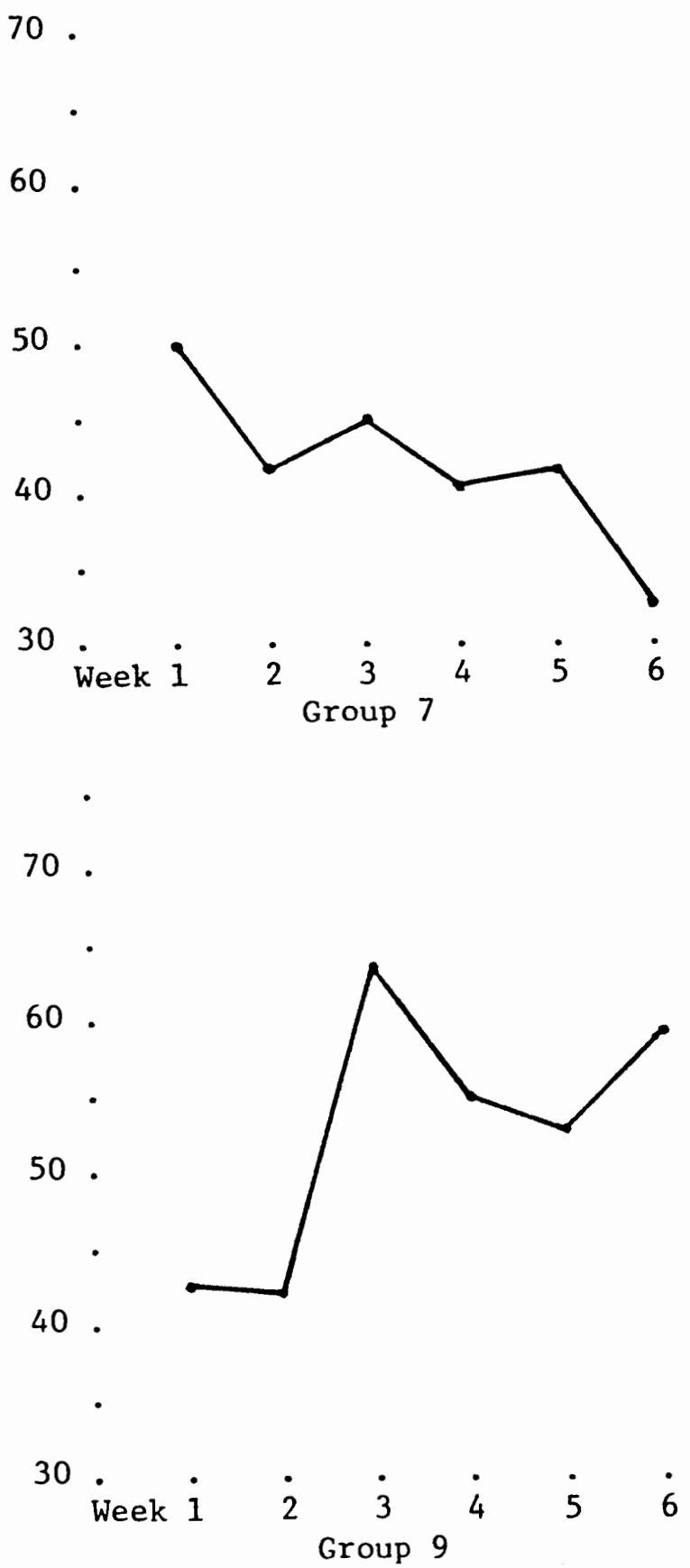

Figure 5. Frequency of self-disclosure per group, per week.

Data from Table $I$ and Figure 5 show the summary of self-disclosure frequencies over the six weeks of investigation. Results show:

1. Frequency of self-disclosure did not show a significant increase over time. Rather, it seemed as though self-disclosure was a 
highly fluctuating variable in group discussion.

2. The nul1-hypothesis was supported by Group 7 in that selfdisclosure appeared to decrease over time. The other four groups showed a pattern of random fluctuation.

Several factors can account for the lack of significant findings from testing hypothesis one. The investigation results were effected by the following phenomena:

1. Reciprocity of self-disclosure was discussed in the review of the literature. It was stated that self-disclosure does not occur capriciously, but it does tend to be preceded or followed by other self-disclosing statements (cf. pg. 8). This reciprocity effect has been frequently demonstrated and seems to override the influence of any individual or group difference variables.

With this in mind, it must be noted that the present investigation used ten adult subjects to aid in group discussion. These adult subjects varied in age, marital status, sex, and youth work experience. In short, each adult brought his or her own personal style of communication into the small group setting. Some of the adults had more gregarious and outgoing personalities than others. Some felt very comfortable and confident being with Senior High youth, while others were "settling in" to relating to this age group. Since the investigation was conducted outside the laboratory, controls were not placed on these individual difference variables. Thus, some of the leaders naturally disclosed more of themselves than others, which undoubtedly evoked further disclosure from the youth in a reciprocal manner. On a night when an adult subject had had a nice day and was "feeling good," disclosures may have been extensive, which in turn may have evoked more 
disclosures from the youth. On the other hand, if the adult came to the group tired or discouraged, chances are his or her disclosures may have been minimal, evoking less disclosure from the youth.

2. Another factor influencing the frequency of self-disclosure was the lack of $100 \%$ attendance for the groups from week to week. When some of the youth were gone due to school activities or family requirements, morale in some of the groups dropped, effecting the youth's desire to open-up and participate whole heartedly in the group discussion.

3. Not only did absenteeism effect disclosure frequencies, but if one of the youth brought a friend into his small group who was a stranger to other group members, it is likely that a period of adjustment would have been needed in order to reestablish the trust level in the group prior to disclosures. Thus, for part of the small group session members may have been reluctant to open-up as readily as when no strangers were present. This may have accounted for the periodic drops in disclosure frequencies.

4. It is also possible that disclosure frequencies were influenced by the fact that many of these youth were already acquainted with one another from school and from the large youth group setting. This could account for the lack of a systematic increase in disclosure from week to week. Since some of them knew each other already, it is easy to understand why statistics from some groups during week one didn't have the lowest disclosure frequencies as compared to the frequencies of weeks two through six.

5. One final factor influencing the frequency of self-disclosure is worth noting. Each week the small group sessions were preceded 
by a large group teaching time. Teachings varied from week to week in terms of subject matter and content. It is possible that one Bible teaching may have been more interesting or more thought provoking to the youth than others. This in turn would have effected the small group discussion. A "hot issue" in the adolescent's minds may have been easier to disclose about than a less interesting subject. This may have accounted for the fluctuation in disclosure frequencies as found in the statistical results.

The above paragraphs summarize some of the intervening variables that could have accounted for the lack of significant findings from the results of testing Hypothesis One. Attention will now be given to Hypothesis Two.

Hypothesis 2. Initial frequency of self-disclosing communication and eventual degree of attraction-to-group will exhibit a strong positive association. That is, higher frequencies of self-disclosure will be followed by greater attraction-to-group.

To test this hypothesis, self-disclosure frequency data were compiled as shown above in Table I and Figure 5. Following this procedure, response scores from the adult and adolescent attractionto-group measures were tabulated for the same five groups. Serial values were assigned to the response categories for each question in the adolescent measure, with the value "4" assigned to the most favorable category. Responses to the four questions were then combined by simple summation of response category values to form an index of attraction-to-group. The adult measure was treated separately with one serial value given in response to the level of attraction-to-group 
the adult perceived during each session. A response of "4" indicated the highest level of attraction possible. Group means and standard deviations were then calculated, giving the distribution of indexes shown in Table II.

TABLE II

DISTRIBUTION OF GROUPS MEAN \& STANDARD DEVIATION INDEX OF ATTRACTION-TO-GROUP

\section{Group 2}

\begin{tabular}{|c|c|c|c|c|c|c|}
\hline Week & 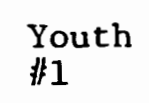 & $\begin{array}{l}\text { Questionnaire } \\
\quad \geqslant 2\end{array}$ & $\begin{array}{l}\text { Item } \\
\# 3\end{array}$ & $\begin{array}{r}\text { Number } \\
\text { 非 }\end{array}$ & Net & $\begin{array}{l}\text { Adult } \\
\text { Measure }\end{array}$ \\
\hline 1 & $\begin{array}{r}3.60 \\
.55\end{array}$ & $\begin{array}{r}3.40 \\
.55\end{array}$ & $\begin{array}{r}3.20 \\
.45\end{array}$ & $\begin{array}{r}3.60 \\
.55\end{array}$ & 3.45 & 3.50 \\
\hline 2 & $\begin{array}{r}3.71 \\
.49\end{array}$ & $\begin{array}{r}3.71 \\
.49\end{array}$ & $\begin{array}{r}3.29 \\
.76\end{array}$ & $\begin{array}{r}3.43 \\
.53\end{array}$ & 3.54 & 4.00 \\
\hline 3 & $\begin{array}{r}4.00 \\
.00\end{array}$ & $\begin{array}{r}3.86 \\
.38\end{array}$ & $\begin{array}{r}3.43 \\
.53\end{array}$ & $\begin{array}{r}3.43 \\
.53\end{array}$ & 3.68 & 3.50 \\
\hline 4 & $\begin{array}{r}3.67 \\
.52\end{array}$ & $\begin{array}{r}3.67 \\
.52\end{array}$ & $\begin{array}{r}3.67 \\
.52\end{array}$ & $\begin{array}{r}3.50 \\
.55\end{array}$ & 3.68 & 4.00 \\
\hline 5 & $\begin{array}{r}4.00 \\
.00\end{array}$ & $\begin{array}{r}4.00 \\
.00\end{array}$ & $\begin{array}{r}3.33 \\
.52\end{array}$ & $\begin{array}{r}3.67 \\
.52\end{array}$ & 3.75 & 4.00 \\
\hline 6 & $\begin{array}{r}4.00 \\
.00\end{array}$ & $\begin{array}{r}3.86 \\
.38\end{array}$ & $\begin{array}{r}3.86 \\
.38\end{array}$ & $\begin{array}{r}3.86 \\
.38\end{array}$ & 3.89 & 4.00 \\
\hline
\end{tabular}


Group 4

Week

Youth Questionnaire Item Number

Adult

1

2

非

非 2

\#3

非

Net

Measure

\begin{tabular}{|c|c|c|c|c|c|}
\hline $\begin{array}{r}3.67 \\
.52\end{array}$ & $\begin{array}{r}3.50 \\
.55\end{array}$ & $\begin{array}{r}3.50 \\
.55\end{array}$ & $\begin{array}{r}3.33 \\
.52\end{array}$ & 3.50 & 3.50 \\
\hline $\begin{array}{r}4.00 \\
.00\end{array}$ & $\begin{array}{r}3.83 \\
.41\end{array}$ & $\begin{array}{r}3.67 \\
.52\end{array}$ & $\begin{array}{r}3.50 \\
.55\end{array}$ & 3.75 & 3.00 \\
\hline $\begin{array}{r}3.86 \\
.38\end{array}$ & $\begin{array}{r}3.71 \\
.49\end{array}$ & $\begin{array}{r}3.86 \\
.38\end{array}$ & $\begin{array}{r}3.71 \\
.49\end{array}$ & 3.79 & 3.50 \\
\hline $\begin{array}{l}3.25 \\
1.39\end{array}$ & $\begin{array}{l}3.25 \\
1.39\end{array}$ & $\begin{array}{l}3.25 \\
1.39\end{array}$ & $\begin{array}{l}3.25 \\
1.39\end{array}$ & 3.25 & 3.00 \\
\hline $\begin{array}{l}3.25 \\
1.39\end{array}$ & $\begin{array}{l}3.25 \\
1.39\end{array}$ & $\begin{array}{l}3.25 \\
1.39\end{array}$ & $\begin{array}{l}3.25 \\
1.39\end{array}$ & 3.25 & 3. \\
\hline $\begin{array}{r}3.67 \\
.82\end{array}$ & $\begin{array}{r}3.83 \\
.41\end{array}$ & $\begin{array}{r}4.00 \\
.00\end{array}$ & $\begin{array}{r}4.00 \\
.00\end{array}$ & 3.88 & 3. \\
\hline
\end{tabular}

Group 6

Youth Questionnaire Item Number

Week 非

\#2

非

\#14

Net

Adult

1

3.56

3.67

3.44

.53

3.56

3.56

Measure

2

.88

.71

.53

2

3.78

3.89

.33

3.22

3.33

3.56

4.00

3

.67

.44

.50

3.50

3.38

.92

3.63

3.63

.52

4

3.86

3.86

.38

3.71

.49

3.71

.49

5

3.67
.50

3.67

3.89

.33

3.89

.33

6

$\begin{array}{rrrr}3.88 & 3.75 & 4.00 & 3.88 \\ .38 & .46 & .00 & .35\end{array}$

.35

3.58

3.00

4.00

3.79

4.00

3.78

3.00

3.88

4.00 
Group 7

\begin{tabular}{|c|c|c|c|c|c|c|}
\hline Week & $\begin{array}{l}\text { Youth } \\
\text { 非 }\end{array}$ & $\begin{array}{l}\text { Questionnaire } \\
\text { 非 }\end{array}$ & $\begin{array}{l}\text { Item } \\
\text { 非 }\end{array}$ & $\begin{array}{r}\text { Number } \\
\text { 非 }\end{array}$ & Net & $\begin{array}{l}\text { Adult } \\
\text { Measure }\end{array}$ \\
\hline 1 & $\begin{array}{r}3.38 \\
.92\end{array}$ & $\begin{array}{r}2.88 \\
.35\end{array}$ & $\begin{array}{r}3.25 \\
.46\end{array}$ & $\begin{array}{r}3.00 \\
.00\end{array}$ & 3.12 & 3.00 \\
\hline 2 & $\begin{array}{r}3.67 \\
.52\end{array}$ & $\begin{array}{r}3.33 \\
.52\end{array}$ & $\begin{array}{r}3.50 \\
.55\end{array}$ & $\begin{array}{r}3.00 \\
.63\end{array}$ & 3.38 & 2.00 \\
\hline 3 & $\begin{array}{r}3.29 \\
.73\end{array}$ & $\begin{array}{r}3.43 \\
.65\end{array}$ & $\begin{array}{r}3.21 \\
.43\end{array}$ & $\begin{array}{r}3.07 \\
.47\end{array}$ & 3.25 & 2.00 \\
\hline 4 & $\begin{array}{l}2.91 \\
1.14\end{array}$ & $\begin{array}{l}3.00 \\
1.18\end{array}$ & $\begin{array}{r}3.09 \\
.30\end{array}$ & $\begin{array}{r}3.18 \\
.60\end{array}$ & 3.05 & 3.00 \\
\hline 5 & $\begin{array}{r}3.33 \\
.87\end{array}$ & $\begin{array}{r}3.44 \\
.53\end{array}$ & $\begin{array}{r}3.11 \\
.33\end{array}$ & $\begin{array}{r}3.56 \\
.53\end{array}$ & 3.36 & 3.00 \\
\hline 6 & $\begin{array}{r}3.63 \\
.74\end{array}$ & $\begin{array}{r}3.63 \\
.52\end{array}$ & $\begin{array}{r}3.75 \\
.46\end{array}$ & $\begin{array}{r}3.75 \\
.46\end{array}$ & 3.69 & 4.00 \\
\hline
\end{tabular}

Group 9

Week

Youth Questionnaire Item Number 非

非 2 \#3

非 4

3.67

.52

3.33

.82

.41

.82

4.00

.00

3.80

.45

3.80

.45

3.60

.55

3

4

5

5

3.40

3.00

.00

3.40

.55

3.20

.45

3.86
.38

3.86

.38

3.71

3.29
.76

3.57

.53

3.71

.49

3.70

.48

3.80
.42
3.14
.38

3.00

.58

3.50

.53

3.60

.52

Data from Table II show:

(1) According to the adolescent measure, four of the five groups $(2,4,6$, and 7$)$ had the highest scores for attraction-to-group during the last week of the 6 week investigation. Although the variation numerically is slight between net scores, it does appear that in 
general, a systematic increase in attraction-to-group for the youth occurred over the six week period. Group 9 showed a pattern of fluctuation in attraction-to-group rather than a steady increase. Thus, data show a low positive but non-significant rise in attraction-to-group.

Significant trends of attraction-to-group increase or decrease may not have been found because of a possible inherent insensitivity in the measure being used. Though the measure was simple and easy for adolescents to understand and complete, it may not have been sensitive enough to pick up the minor variations in feelings of attraction-togroup from week to week. It is also possible that the youth became desensitized to the instrument having completed it time after time for six consecutive weeks.

In addition, the attraction-to-group scores were calculated by the summation of individual responses to the group sessions. There were some instances where three-fourths of the group rated the group's attractiveness as " 4 " and the other members of the group rated it as "1." Accordingly, total group scores were highly effected by one or two "extreme" responses. These extreme responses can be noted as a cause for the slight discrimination found between group scores.

(2) According to the adult measure, four of the five adult subjects (those in group 4,6,7 and 9) gave their sixth session the highest possible rating. Aside from this high overall rating for session six no significant trend can be seen. It is possible that the adult attraction-to-group measure was also not sensitive enough to pick up minor variations of attraction-to-group feelings from week to week. It might prove to be more beneficial in future studies to use more detailed self-report questionaires for adult subjects. The adults 
in this study may also have been gradually desensitized to the test instrument as they completed it week after week.

Another point to consider regarding the adult's perception of attraction-to-group each session is the frame of mind each adult had going into the group setting. It is likely that fatigue, stress, discouragement, self-consciousness, elation or joy clouded the perception of attraction-to-group from time to time. Thus, one adult may have entered the group after a bad day at work and rated the group's attraction level lower than if he had just received a raise from the boss. This may have accounted for the periodic times when youth attraction-to-group scores were high at the same time the adult scores were 1ow. Outside a laboratory setting, it was difficult, if not impossible to control these intervening factors.

(3) When comparing adolescent net measures with adult ratings, four of the five groups $(2,6,7$, and 9) showed compatability in judgment in that both adults and youth subjects had the highest rating during the sixth session. However, no significant comparisons occurred overall during the other five weeks of meetings. These results seemed to indicate that most of the time, the youth were perceiving attractionto-group quite differently than the adult subjects, as their contrasting scores reflected. Several reasons for this incompatability in scoring can be speculated:

A. It is possible that the degree of closeness or attraction the adults were expecting in the group was higher than what the youth were expecting. This would account for the lower scoring on the adult's . part and higher scoring from the youth. Perhaps the adults felt an unspoken pressure of making sure their group was a success, and thus 
expected too much out of the half-hour sessions. On the other hand, some youth may not have felt any particular desire to have a. real cohesive group and thus expected very little out of the small group sessions.

B. Attraction-to-group is an abstract concept, and since the definition of an "ideal group session" was never set forth, a lack of clarity may have surrounded the adult's and youth's understanding of how they were supposed to feel and interact during the group sessions. This would have effected their scoring.

C. Another problem which effected the attraction-to-group was the absenteeism from the groups. Outside of the laboratory setting it was impossible to maintain $100 \%$ attendance of all the groups every week. School activities, and requirements from parents accounted for the absenteeism experienced in all of the groups. Depending on which individuals were absent, attraction-to-group scores were likely to have fluctuated. If a more outgoing, well-liked and talkative young person was absent, others in the group no doubt felt the "loss" and sensed that some of the "glue" was missing from their meeting. This problem influenced the results in the present investigation, and accounted for part of the explanation for failure to achieve significant comparisons.

Having separately stated and discussed the results found from the self-disclosure data, and attraction-to-group scores, attention will now be given to the correlation of the above data. Attraction-to-group indexes were correlated with frequency of self-disclosure. Table III below shows the degree of intercorrelation between both indices, including a table from both tape raters, and a composite correlation of 
all five group's frequency of self-disclosure with attraction-to-group measures.

TABLE III

OVFRALL CORRELATIONS OF FREQUENCY OF SELF-DISCLOSURE WITH ATTRACTION-TO-GROUP

\begin{tabular}{lcc} 
Level & Group & Leader \\
I & .177 & .074 \\
III & .010 & .234 \\
Cum. & .252 & .188 \\
Questions & .193 & .230 \\
Judge \#1 & .021 & .148 \\
& & .114 \\
I & .060 & .311 \\
II & .194 & .033 \\
III & .096 & .255 \\
Cum. & .188 & .117 \\
Questions & .053 & \\
Judge \#2 & & \\
\hline
\end{tabular}


TABLE III Continued

\begin{tabular}{lcc}
\multicolumn{3}{c}{ Composite Correlations of all Group } \\
Self-disclosure Frequency with Attraction-to-Group \\
Level & Group & Leader \\
I & .123 & .099 \\
II & .099 & .283 \\
III & .118 & .104 \\
Cum. & .191 & .244 \\
Questions & .037 & .133
\end{tabular}

The hypothesis now being considered is: A strong positive association will be observed between initial frequency of self-disclosure and the eventual degree of attraction-to-group. That is, higher frequencies of self-disclosure will be followed by greater attraction-togroup. Results in Table III show:

1. Correlations between adolescent measures of attraction-togroup and frequency of self-disclosure were not statistically significant.

2. Correlations between adult measures of cohesion and frequency of self-disclosure were not statistically significant.

Thus, a strong positive association was not observed between initial frequency of self-disclosing communication and eventual degree of attraction-to-group, and higher frequencies of self-disclosure did not have a significant effect on greater levels of attraction-to-group. It is unlikely that significant results would have been detected in the correlation of these two variables, when neither variable tested on their own produced significant results.

Results have been stated and discussion has been given concerning Hypothesis One and Two. Attention will now be given to Hypothesis Three. 
Hypothesis 3. Self-disclosure and attraction-to-group will co-vary over time, that is: 1. As self-disclosure increases, attraction-togroup will increase; 2. As self-disclosure decreases, attraction-togroup will decrease; and 3. As self-disclosure fluctuates, there will by a systematic fluctuation in attraction-to-group.

Response scores from the adolescent and adult attraction-togroup measures, and frequency level of self-disclosure are graphed below in Figure 6.

80 .

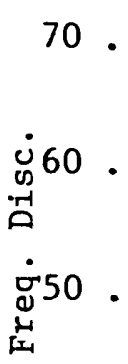

40 .

30 .

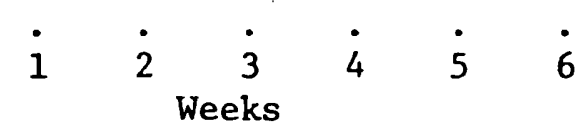

80 .

Group 4

70
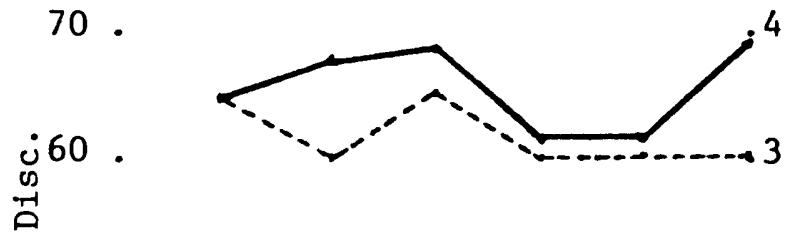

$\dot{8} 50$

点

40 .

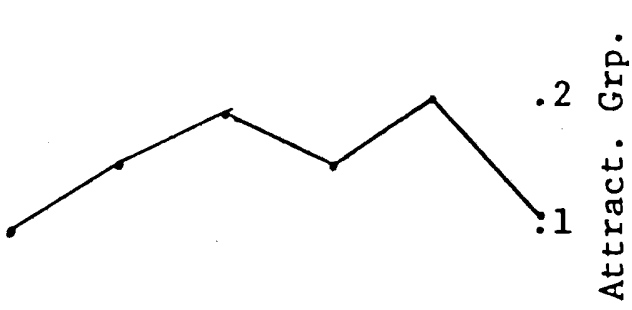

30 .
Group 2

Frequency of Disclosure denoted by

Attraction-to-Group Adult score denoted by -..--.-

Youth score denoted by

Frequency of Disclosure denoted by

Attraction-to-Group Adult score denoted by -........

Youth score denoted by

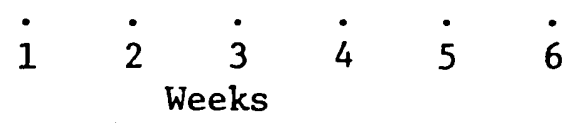


80 .

Group 6

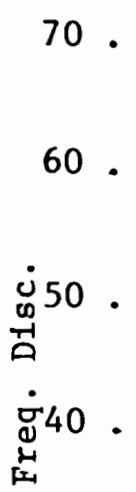

30 .

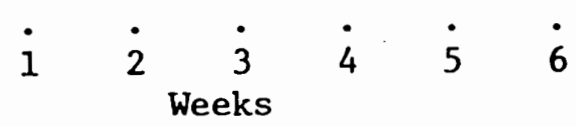

80 .

70 .

60 .

30 .

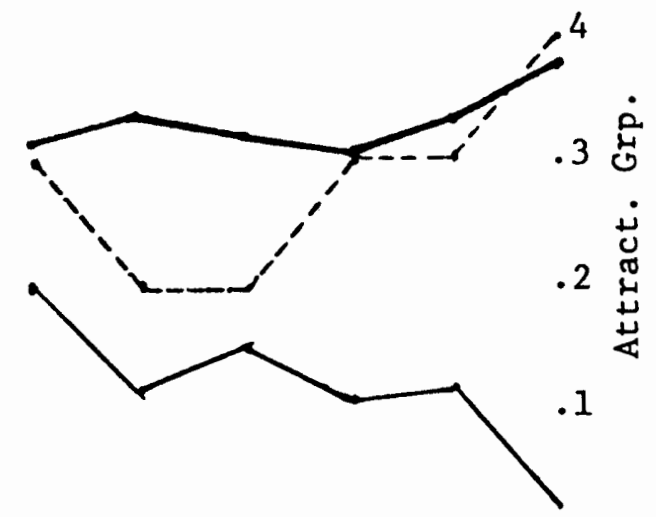

\section{Group 7}

Frequency of Disclosure denoted by

Attraction-to-Group Adult score denoted by - - - - -

Youth score denoted by
Frequency of Disclosure denoted by

Attraction-to-Group Adult score denoted by

Youth score denoted by

$\begin{array}{llllll}1 & \dot{2} & 3 & \dot{4} & 5 & 6\end{array}$

Weeks 


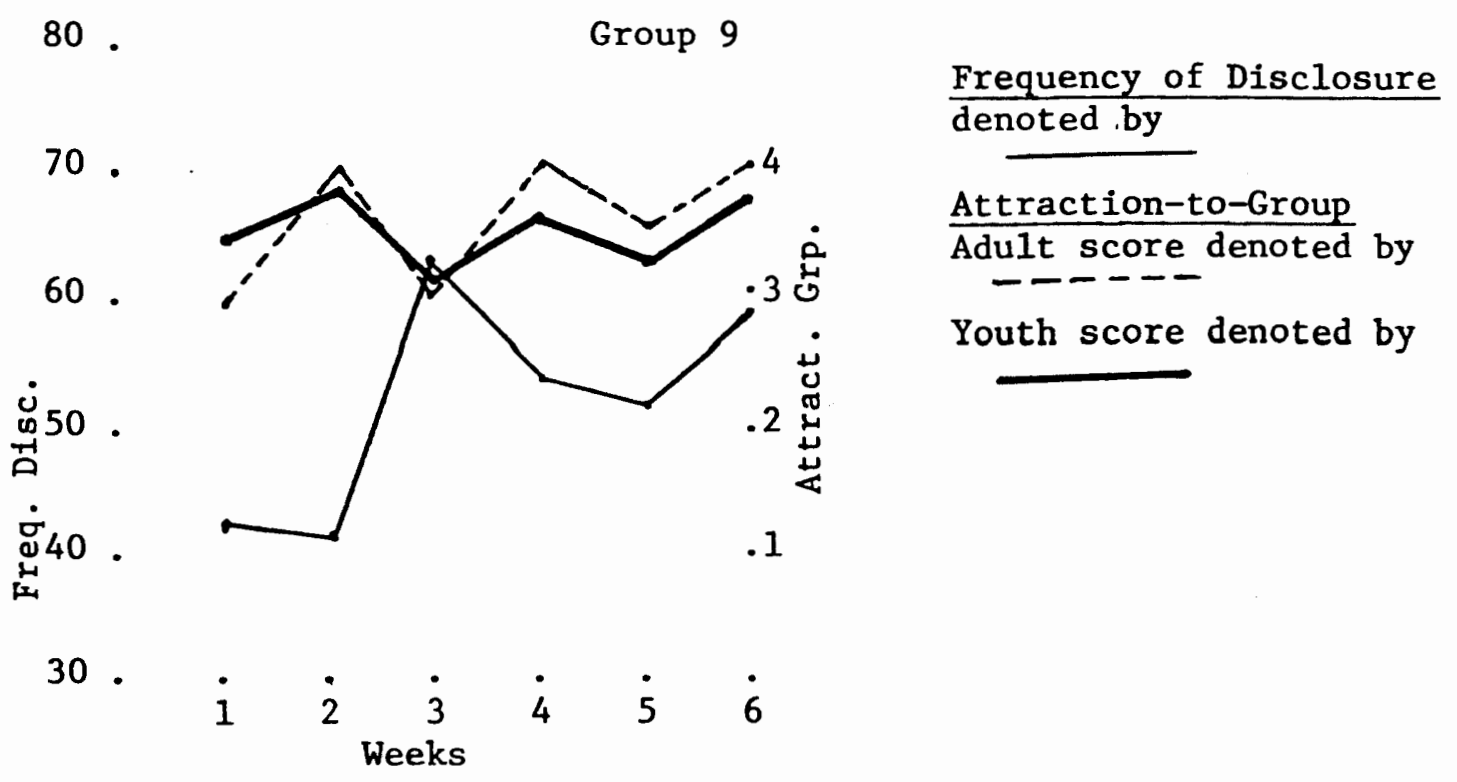

Figure 6. Attraction-to-group and self-disclosure frequencies graphed

Figure 6 shows the summary of correlations between frequency of self-disclosure and attraction-to-group scores. As seen in the figure:

1. Increased frequency of self-disclosure did not have a significant effect on increase of attraction-to-group.

2. Decreased frequency of self-disclosure did not have a significant effect on decreases in attraction-to-group.

3. There were no significant correlations showing systematic fluctuation between the two variables.

As stated earlier, due to the fact that the investigation was conducted outside the laboratory setting wherein several interacting variables were not controlled for, significant results from the hypotheses tested were minimal. The data did show a low positive but non-significant rise in attraction-to-group scores over the six weeks period. This rise occurred regardless of a rise or fall in selfdisclosure frequencies.

It is interesting that group 6 data revealed the highest measure 
of attraction-to-group given was during week 6, the same week that self-disclosure frequencies were the lowest. This may have been due to a desensitization to the attraction measure by the sixth week. It is also possible that the young people had built a loyalty to the adult member by the sixth week and were therefore more sensitive to the feelings of the adult than to their own honesty in filling out the questionaire. They may have felt they would hurt the feelings of the adult member if the scores they marked were low. Another possibility is that the youth had experienced a "fun" and "light" time of discussion in their group that night which resulted in high attraction scores, even though the discussion may have consisted mainly of level one disclosures.

Summary

The present investigation was developed in order to study the effect of self-disclosing communication on the attraction to the group felt by members in the small group setting. This section recapitulates the key questions of the present thesis with discussion given to inherent problems and to beneficial results derived from the study. It is first necessary to state the results of the study did not confirm the three hypotheses: 1. Frequencies of self-disclosure did not increase over time. Results showed a random fluctuation of disclosure frequencies in all the groups over the six weeks of investigation; 2. Initial frequency of self-disclosing communication and eventual degree of attraction-tó-group did not exhibit a strong positive association. That is, higher frequencies of self-disclosure were not followed by greater attraction-to-group. One group revealed the opposite results during week six of the study. The group members 
gave the highest attraction scores that week and yet the disclosure frequency was the lowest it had been during the entire six weeks; 3 . Self-disclosure and attraction-to-group did not co-vary over time. That is, as self-disclosure frequencies increased, attraction-to-group scores did not increase. As self-disclosure frequencies decreased, attractionto-group scores did not decrease, and as self-disclosure fluctuated, there was not a systematic fluctuation in attraction-to-group scores. There are several possible explanations for these results. Most important is the fact that the investigation was conducted in a natural setting outside a controlled laboratory environment which limited significant findings. Several interacting factors which influenced the study results were: (1) the individual differences among adult subjects in personality and natural disclosure patterns of communication, in their confidence relating to Senior High youth and the "frame of mind" they had when entering the small group setting; (2) the attendance fluctuation with some youth being absent due to family and school requirements, or some youth bringing friends (strangers) into the small group setting; (3) the prior acquaintances among the youth from school and church; (4) that variety of subject matter taught by the Youth Director from week to week prior to the small group sessions; (5) a desensitization of the youth and adults to the attraction-to-group measures used for six consecutive weeks; (6) an insensitivity in the testing instruments to detect minor fluctuations and variations in group members feelings; and (7) the difference in the adult's and young people's perception and expectation of the concept "attraction-to-group." 
Participant benefits of the study

Though the testing results revealed no significant trends regarding the effects of self-disclosure frequencies on attraction-togroup, several findings of personal interest gleaned from the investigation are worth noting: (1) The division of the Youth Department into small groups worked to the advantage of the youth. Fewer adolescents were "lost in the crowd" and most youth had opportunity to interact with others on a personal level; (2) The division of the Youth Department into small groups worked to the advantage of the adult group members. This allowed them an opportunity for more intimate and lengthy communication with the youth, and the chance to experience more frequent disclosures from the young people; (3) The small groups worked to the advantage of the Youth Director by allowing him the opportunity to hear the group communications on tape. From this procedure, strengths and weaknesses of the adult's facilitation styles were detected. This information provided a launching point for a leadership training course designed by the Youth Director and the writer for the improvement of skills in small group facilitation. The workshop was conducted following the completion of the present investigation. Through this course, the adult subjects learned first hand from listening to and discussing their own taped sessions and other group sessions. They discovered in the process new techniques for group communication and various procedures that have a negative impact on group communication with teenagers. It was especially beneficial for the adults to hear the way the others facilitated their group discussions. (4) The investigation worked to the advantage of the writer by giving her opportunity to learn the procedures involved 
in conducting a quantitative study. After some changes have been made, the writer plans to reproduce this study design in a laboratory setting with young people in Growth Groups at a Portland Counseling Center. Controls will be placed on those variables which interacted in the present study in order to insure more stable testing procedures. Some of the changes to be made in the replication of this study design are worth noting at this point. To begin, attendance will be controlled at the Counseling Center. Once the Teen Growth Groups are formed no new members will be accepted into the groups during the eight weeks they are in session. Since a fee is involved in being a member in a Growth Group and attendance is mandatory among group members, it is likely that the attendance index will be stable. In addition, personality differences between various facilitators will be controlled for, as the writer will be the only person facilitating the teen groups. Furthermore, group goals will be better defined than in the present experiment so that both the facilitator and the teen members have a clear understanding of the purpose of the group. A final factor that will not be a problem in the future replication of this study is a desensitization of the young people to the attractionto-group measure. To control for this, another instrument will be used in addition to Seashore's (1954) Measure to achieve more accurate statistical data on the member's attraction to the group. Schutz's (1973) Cohesiveness Measure is a more detailed index of attraction-togroup and could be easily administered following the first and last session of the Growth Groups. With these considerations in mind, attention will now be given to suggestions for future research. 
Suggestions for future research

It is clear from the evidence of everyday life that people can not interact socially without disclosing something of themselves or being affected by what others disclose to them. It is this interactional nature of self-disclosure that has made it such an important behavior for study. This section will highlight some possible points of departure for future reserach concerning self-disclosure and attractionto-group.

One problem apparent in the literature review of self-disclosure is the confusion of what objectively constitutes self-disclosure. The concept is surrounded with a lack of clarity, and this has resulted in contradictory findings in self-disclosure research. The definition of self-disclosure chosen for this study was Cosby's (1973), stated in these words: Self-disclosure is any information Person A verbally communicates to Person B. This definition served the purposes of this study, however it does not differentiate non-disclosure from disclosure phenomena, such as the way we dress, certain gestures, body posture, interaction space, and the like. Most of the studies to this point have been done on those factors which operate to promote or evoke self-disclosure. Other studies are needed on those factors which would operate to inhibit disclosure in dyadic as well as in group encounters.

It is also important to note that the present study dealt specifically with oral disclosures made within the small group setting. Other research is needed on self-disclosure in groups where multiple parameters of disclosure are examined such as non-verbal mannerisms, verbal disclosures, time spent in disclosing, and intimacy of disclosures, to name a few. A study incorporating analysis of these various 
factors would lend further understanding to the relative contributions each characteristic makes to the overall perception of self-disclosure. A variety of types of assessment measures could be incorporated using self-report and observer ratings for data collection.

In addition to the need for further research on self-disclosure, there is also a need for further studies on the variable, attractionto-group. As stated in the literature review, the concept attractionto-group was often found embedded in research concerning group cohesion. In some instances the 2 terms were used synonymously. Not only did this confound the meaning of attraction-to-group and cohesion, but it also made clear measurement of either variable a difficult task. One recent study (Evans and Jarvis, 1980) proposed that the two variables be investigated separately as two different phenomena in group process. Few investigations have separated the concepts to this date, and no studies are currently available which separate the concepts and systematically investigate both variables in one experiment. It is logical to assume that some theory building is needed concerning these concepts before more studies are done to catalog the determinants or the effects of cohesion and attraction-to-group. With the development of new theory, experiments designed to explain the differences in group cohesion and attraction-to-group would be very helpful for those interested in this important phenomenon of group process.

In regards to both self-disclosure and attraction-to-group, there is a need for further examination of the variables within everyday social situations outside the laboratory as well as in a treatment context such as group therapy. Questions to be considered are: What is the function of self-disclosure in small groups?; What are 
the advantages and drawbacks of low, moderate, and high disclosures in the small group setting?; What causes high and low levels of attraction in groups?; What other factors of group process are effected by high and low levels of disclosure and attraction-to-group? With additional data we may be able to understand and predict when and why some individuals in groups choose to disclose and when and why some individuals are more attracted to the group than others. This in turn, would aid those who are challenged with the task of successfully facilitating small groups in a variety of contexts, both inside and outside of the laboratory setting. 


\section{REFERENCES}

Albert, R. S. 1953. "Comments on the scientific function of the concept of cohesiveness," American Journal of Sociology, 59: 231-234.

Altman, I., and Hawthorn, W. W. 1966. "Interpersonal exchange in isolation," Sociometry, 28: 411-426.

Altman, I., and Taylor, D. A. 1973. Social Penetration: The development of interpersonal relationships. New York: Holt, Rinehart, and Winston.

Anchor, K. N. Vojtisek, J. E., and Berger, S. E. 1972. "Social desirability as a predictor of self-disclosure in groups," Psychotherapy: Theory, Research, and Practice, 9: 262-264.

Back, K. W. 1951. "Influence through social communication," Journal of Abnormal and Social Psychology, 46: 9-23.

Bednar, R. L. and Lawlis, G. 1971. "Empirical research in group psychotherapy," Behavior Change. New York: John Wiley.

Berberich, R. R., Gabel, H., and Anchor, K. N. 1979. "Self-disclosure in reflective, behavioral and discussion parent counseling groups," Journal of Community Psychology, 7: 259-263.

Cartwright, D. and Zander, A. 1960. Group Dynamics Research and Theory. Evanston, Illinois: Row, Peterson and Company.

- 1968. Group Dynamics Research and Theory. 2nd edition. Evanston, Illinois: Row, Peterson and Company.

Certner, B. C. 1971. "The exchange of self-disclosure in same sexed and heterosexual groups of strangers," Dissertation Abstracts International, 31: (9-A), 4885.

Cosby, P. 1973. "Self-disclosure: A literature Review," Psychological Bulletin, 79: 73-91.

Chelune, G. L. 1979. Self-disclosure. San Francisco, California: Jossey - Bass.

Dies, R. R. and Cohen, L. 1976. "Content considerations in group therapist self-disclosure," International Journal of Psychotherapy, 26: 71-88.

Doster, J. A. and Nesbitt, J. G. 1979. "The theoretical relationship between self-disclosure and psychotherapy," in G. Chelune (ed.) 
Self-Disclosure. San Francisco, California: Jossey - Bass.

Egan, G. 1970. Encounter: Group Processes for Interpersonal Growth. Belmont, California: Brooks and Cole.

Evans, N. J. and Jarvis, P. A. 1980. "Group Cohesion: A review and reevaluation," Small Group Behavior, 11: 359-370, California: Sage Publications.

Festinger, L. 1950. "Informal social communication," Psychological Review, 57: 271-282.

Gerard, L. B. 1951. "The use of a sociometric test as a predictor of combat unit effectiveness," Sociometry, 16: 168-179.

Gibb, J. R. 1961. "Defense level and influence potential in small groups," in L. Petrullo and B. M. Bass (eds.) Leadership and Interpersonal Behavior. New York: Holt, Rinehart, and Winston Inc.

Gibb, J. R. and Gibb, L. M. 1969. "Role freedom in a TORI group," in A. Burton (ed) Encounter: The theory and practice of encounter groups. San Francisco, California: Jossey - Bass.

Goodacre, G. M. 1953. "Group characteristics of good and poor performing combat units," Sociometry, 16: 168-179.

Gross, N. and Martin, W. E. 1952. "On group cohesiveness," American Journal of Sociology, 57: 546-554.

Hare, P. A. 1976. Handbook of Small Group Research. 2nd ed. New York: The Free Press.

Johnson, D. W. and Johnson, F. P. 1975. Joining Together: Group Theory and Group Skills. New Jersey: Prentice - Hall.

Johnson, J. 1963. Group Therapy: A practical approach. New York: McGraw Hill.

Jourard, S. M., and Lasakow, P. 1958. "Some factors in self-disclosure," Journal of Abnormal and Social Psychology, 56: 91-98.

, and Landsman, M. J. 1960. "Cognition, cathexis, and the 'dyadic effect' in men's self-disclosing behavior," MerrillPalmer Quarterly, 6: 178-186.

- 1964. The transparent self. Princeton: Van Nostrand.

, and Friedman, R. 1970. "Experimenter - subject

'distance' and self-disclosure," Journal of Personality and Social Psychology, 15: 278-282.

- 1971. Self-disclosure: An experimental analysis of the transparent self. New York: Wiley - Interscience. 
Kangas, J. A. 1971. "Group member's self-disclosure; a function of preceding self-disclosure by leaders on other group members," Comparative Group Studies, 2: 65-70.

Kirshner, B. J. 1976. "The effects of experimental manipulation of self-disclosure on group cohesiveness," Dissertation Abstracts International, 37: (6-B), 3081-3082.

Lange, J. I. 1981. "Sociometric and autonomic responses to three levels of self-disclosure in dyads." Western Journal of Speech Communication, 45: 355-362.

Lefkowitz, M. B. 1970. "The role of self-disclosure and physical attractiveness in person-perception," in G. Chelune (ed.), Self-disclosure. San Francisco, California: Jossey - Bass.

Lewin, L. 1939. "Field theory and experiment in social psychology: concepts and methods," American Journal of Sociology, 44: 868-896.

Libo, L. M. 1953. Measuring Group Cohesiveness. Ann Arbor, Michigan: Research Center for Group Dynamics.

Lieberman, M. A., Yalom, I. D. and Miles, M. B. 1973. Encounter Groups: First Facts. New York: Basic Brooks.

Locke, N., Slavson, S. Schwartz, S., and Wolff, P. 1974. "Non-disclosure and facilitation," in J. B. Shaffer and M. D. Galinsky (eds.) Models of Group Therapy and Sensitivity Training. Englewood Cliffs, New Jersey: Prentice - Hall.

Mendenhall, w. 1967. Introduction to Probability and Statistics. Belmont, California: Wadsworth Publishing Company.

Miller, D. C. 1970. Handbook of Research Design and Social Measurement. New York: David Mckay.

Pearce, W. B., and Sharp, S. M. 1973. "Self-disclosing communication," The Journal of Communication, 23: 409-425.

Polansky, N. A. 1967. "On duplicity in the interview," American Journal of Orthopsychiatry, 37 : 568-580.

Rogers, C. R. 1961. On Becoming a Person. Boston: Houghton Mifflin. - 1970. Carl Rogers on Encounter Groups. New York: Harper and Row.

Rosenfeld, R. 1979. "Self-disclosure avoidance: Why I am afraid to tel1 you who I am," Communication Monographs. 46: 63-74.

Schachter, S. 1951. "Deviation, rejection, and communication," Journal of Abnormal and Social Psychology, 46: 190-207. 
Schutz, W. C. 1973. Elements of Encounter. California: Joy Press.

Seashore, S. 1954. Group Cohesiveness in the Industrial Work Group. University of Michigan.

Shaffer, J. B. and Galinsky, M. D. 1974. Models of Group Therapy and Sensitivity Training. Englewood Cliffs, New Jersey: Prentice - Hall.

Silverman, M. L. 1979. "The effects of three kinds of disclosure activites on intimacy in small groups," Dissertation Abstracts International, 39: (11-B), 5664 .

Strassberg, D. S. and Anchor, K. N. 1975. "Rating intimacy of selfdisclosure," Psychological Reports, 37: 562.

Strassberg, D. S., Roback, H. B., Anchor, K. N., and Abramowitz, S. I. 1975. "Self-disclosure in group therapy with schizophrenics," Archives of General Psychiatry, 32: 1259-1261.

Strassberg, D. S., Gabel, H., and Anchor, K. N. 1976. "Patterns of self-disclosure in parent discussion groups," Small Group

Behavior, 7: 259-263.

Taylor, D. A. and Altman, I. 1966. "Intimacy scaled stimuli for use in studies in interpersonal relations," Psychological Reports, 19: $729-730$.

Taylor, D. A. 1968. "The development of interpersonal relationships: social penetration processes," Journal of Social Psychology, 75: 79-90.

Taylor, D. S., Altman, I. and Sorrentino, R. 1969. "Interpersonal exchange as a function of rewards and costs and situationa1 factors: expectancy confirmation-disconfirmation," Journal of Experimental Social Psychology, 5: 324-339.

Traux, C. B. and Carkhuff, R. R. 1965. "Client and therapist transparency in the psychotherapeutic encounter," Journal of Counseling Psychology, 12: 3-9.

VanBergen, S., and Koekebakker, N. 1959. "Group cohesion: a review and reevaluation," in N. J. Evans and P. A., Jarvis (eds.) Smal1 Group Behavior, 11: 359-370. California: Sage Publications.

Vondracek, S. I., and Vondracek, F. W. 1971. "The manipulation and measurement of self-disclosure in pre-adolescents," Merill Palmer Quarterly, 17: 51-58.

Vosen, L. M. 1979. "The relationship between self-disclosure and self-esteem," in G. Chelune (ed.) Self-disclosure. San Francisco, California: Jossey - Bass. 
Worthy, M., Gary, A. L., and Kahn, G. M. 1969. "Self-disclosure as an exchange process," Journal of Personality and Social Psychology, 13: $59-63$. 
APPENDIX 
APPENDIX

STRASSBERG-ANCHOR INTIMACY RATING SCALE (IRS)

I. Low-Content Self-Disclosure

A. Demographic Public Information (Name, age, religion, occupation, address, height, weight, marital status, etc.)

B. Daily Habits and Preferences (e.g., smoking)

C. Schooling

D. Interests (television, sports)

E. Hobbies and other leisure time activites

F. Fashion (i.e., preferences)

1. Make-up

G. Personal hygiene, health and maintenance

H. Physical characteristics

I. Vocational preferences

$\mathrm{J}$. Borrowing and lending behavior

K. Political/economic attitudes

L. Description of events without affect

M. Aesthetics

N. Geography (e.g., travel plans; location description)

II. Moderately Intimate Self-Disclosure

A. Personal ideology (with relation to how one conducts his/ her life)

1. Religious preferences

2. Moral perspective and evaluation (e.g., euthanasia and killing in time of war)

3. Feelings about the future as it relates to oneself

and significant others (e.g., aging and dying)

4. Superstitions

5. Dreams and non-sexual fantasy

6. Annoyances

B. Life plans

1. Ambitions

2. Aspirations

3. Goals

C. Earlier Life Events (not directly related to one's immediate life situation)

1. School grades and performance

2. Worries, disappointments

3. Successes and accomplishments

4. Rejections and losses

5. Episodes of ridicule

6. Lies told to, by, or about oneself

D. Life style

1. Financial status

2. Discussion of certain sex-related topics

a. Dating, kissing, and fondling

b. Swearing or being the subject of profanity from others 
c. Sex-related humor

E. Illegal or immoral activity of significant others

F. Child Management

G. Names and personality descriptions of self or significant others (e.g., lovers and boyfriends)

H. Admission of minor illegal or anti-social acts

1. Traffic ticket

2. Mistreatment of animals

3. Experimentation with minor drugs (e.g., marijuana) and alcohol

I. Minor psychological or psysical concerns

1. Non-debilitating fears

2. Weight problem and height

3. Failure to take responsibility for oneself

4. Personality characteristics such as trust, immaturity, spontaneity, impulsivity, honesty, defensiveness and warmth

J. Mild emotional states

1. General likes and dislikes

K. Narration of events and experiences that include oneself with affect

III. Highly Intimate Self-Disclosure (tends to be self-referential in nature)

A. Sexual habits and preferences (real or imaginary)

1. Sexual dreams

B. Major disappointments or regrets

1. Discussion of crises in one's life (past or present)

2. Description of counseling or therapy experience (real or contemplated)

3. Shame

C. Admission of serious difficulties (past or present in the expression or control of behavior)

1. Addictions (e.g., excessive use of drugs or alcohol; discussion of habitual use)

2. Physical aggression (given or received)

3. Abortion

D. Important and/or detailed anomalies (physical or psychological)

1. Discussion of previous psychiatric disorder of respondent or significant others

2. False 1imbs, glass eyes, toupees, etc.

3. Serious diseases (current)

E. Important feelings and behaviors (positive and negative) relating to:

1. Marriage and family (parents, children, brothers, and sisters and significant others--e.g., lovers)

2. Reasons for marriage or divorce

3. Extra-marital sexual relations or desire for same (actual or intended)

4. Discussion of parents' marriage

5. Confidential material told to or initiated by respondent 
F. Discussion of specific instances of intense emotion

(directed toward self or others; in personal terms)

1. Feelings of depression

2. Love (if discussed specifically--otherwise, if used in abstract sense, rate II)

3. Hate, bitterness and resentment

4. Anger

5. Elation

6. Fulfillment

7. Extreme fears

8. Very strong personal desires (e.g., to be better liked)

9. Jealousy

G. Discussion of important hurt, loss, or discomfort caused or received by respondent (actual or anticipated)

H. Deep sense of personal worth or inadequacy which significantly affects self-concept

1. Include serious strengths and weaknesses in absolute or relative terms.

2. Rejection by significant others

I. Admission of significant illegal, immoral, or antisocial acts or impulses of self or significant others

1. Stealing

2. Vandalism

3. Important lies

J. Details of important and meaningful relationships (i.e., why someone is your best friend; if significant other is discussed not in relation to oneself, use category I or II) 